\title{
Membrane Distillation: Principle, Advances, Limitations and Future Prospects in Food Industry
}

\author{
Pelin Onsekizoglu \\ Trakya University Department of Food Engineering, Edirne
}

Turkey

\section{Introduction}

Membrane separation processes have become one of the emerging technologies in the last few decades especially in the separation technology field. They offer a number of advantages over conventional separation methods in a wide variety of applications such as distillation and evaporation. Membrane processes can be easily scaled up due to their compact and modular design; they are able to transfer specific components selectively; they are energy efficient systems operating under moderate temperature conditions ensuring gentle product treatment.

Microfiltration (MF), ultrafiltration (UF), nanofiltration (NF), reverse osmosis (RO), pervaporation and electrodialysis are conventional membrane processes that have already gained wide acceptance in food processing (Bazinet et al., 2009; Couto et al., 2011; Gomes et al., 2011; Mello et al., 2010; Quoc et al., 2011; Santana et al., 2011). Membrane distillation (MD) is an emerging thermally driven membrane process in which a hydrophobic microporous membrane separates a heated feed solution and a cooled receiving phase. The temperature difference across the membrane results a water vapour pressure gradient, causing water vapour transfer through the pores from high vapour pressure side to the low one. Some of the key advantages of membrane distillation processes over conventional separation technologies are: relatively lower energy costs as compared to distillation, reverse osmosis, and pervaporation; a considerable rejection of dissolved, non-volatile species; much lower membrane fouling as compared with microfiltration, ultrafiltration, and reverse osmosis; reduced vapour space as compared to conventional distillation; lower operating pressure than pressure-driven membrane processes and lower operating temperature as compared with conventional evaporation (Bazinet et al., 2009; Couto et al., 2011; Gomes et al., 2011; Lawson \& Lloyd, 1996b; Mello et al., 2010; Quoc et al., 2011; Santana et al., 2011).

Dewatering aqueous solutions is one of the key unit operations encountered in food processing, particularly in the processing of beverages, fruit juice, milk, whey, vegetable extracts, etc. The initial soluble solid contents are increased by concentration process, reducing the volume with consequent reduction of transport, storage and packaging costs. In addition, the concentrates are more resistant to microbial and chemical deterioration as a result of water activity reduction. 
Today, multistage vacuum evaporation is the predominant method used for liquid concentration in food industry. The main drawbacks of this system are high energy consumption and heat induced deterioration of sensory (color changes, off-flavor formation) and nutritional characteristics (Ibarz et al., 2011; Kadakal et al., 2002; Simsek et al., 2007; Toribio \& Lozano, 1986; Varming et al., 2004). Recently, technological advances related to the development of new membrane processes including membrane distillation have been proved to overcome this limitation (Bagger-Jorgensen et al., 2011; Cassano \& Drioli, 2007; Hongvaleerat et al., 2008; Kozak et al., 2009; Onsekizoglu et al., 2010b; Valdes et al., 2009).

This chapter will cover the process features, theoretical aspects and the relevant mathematics related to water transport mechanism in membrane distillation. The most basic concepts of osmotic distillation, a membrane distillation variant operating at lower temperature will be also discussed. The suggestions for membrane selection taking into account the membrane material and module configuration together with contact angle and membrane wettability will be presented in detail. The process parameters affecting the transmembrane flux and the most promising applications for enhancement of flux will be highlighted. Applications in food industry and long term performance of membrane distillation systems will be evaluated. The possibility of integrating membrane distillation with other existing processes and suggestions for future work will be presented.

\section{Process fundamentals}

MD is a thermally driven process, in which water vapour transport occurs through a nonwetted porous hydrophobic membrane. The term MD comes from the similarity between conventional distillation process and its membrane variant as both technologies are based on the vapour-liquid equilibrium for separation and both of them require the latent heat of evaporation for the phase change from liquid to vapour which is achieved by heating the feed solution. The driving force for MD process is given by the vapour pressure gradient which is generated by a temperature difference across the membrane. As the driving force is not a pure thermal driving force, membrane distillation can be held at a much lower temperature than conventional thermal distillation. The hydrophobic nature of the membrane prevents penetration of the pores by aqueous solutions due to surface tensions, unless a transmembrane pressure higher than the membrane liquid entry pressure (LEP) is applied. Therefore, liquid/vapour interfaces are formed at the entrances of each pore. The water transport through the membrane can be summarized in three steps: (1) formation of a vapour gap at the hot feed solution-membrane interface; (2) transport of the vapour phase through the microporous system; (3) condensation of the vapour at the cold side membrane-permeate solution interface (Jiao et al., 2004; Peinemann et al., 2010).

Various MD configurations can be used to drive flux (El-Bourawi et al., 2006; Khayet, 2011; Lawson \& Lloyd, 1997; Susanto, 2011; Zhigang et al., 2005). The difference among these configurations is the way in which the vapour is condensed in the permeate side. Figure 1 illustrates the four commonly used configurations of MD described as follows:

1. In direct contact membrane distillation (DCMD), water having lower temperature than liquid in feed side is used as condensing fluid in permeate side. In this configuration, the liquid in both sides of the membrane is in direct contact with the hydrophobic microporous membrane. DCMD is the most commonly used configuration due to its 
Membrane Distillation: Principle, Advances,
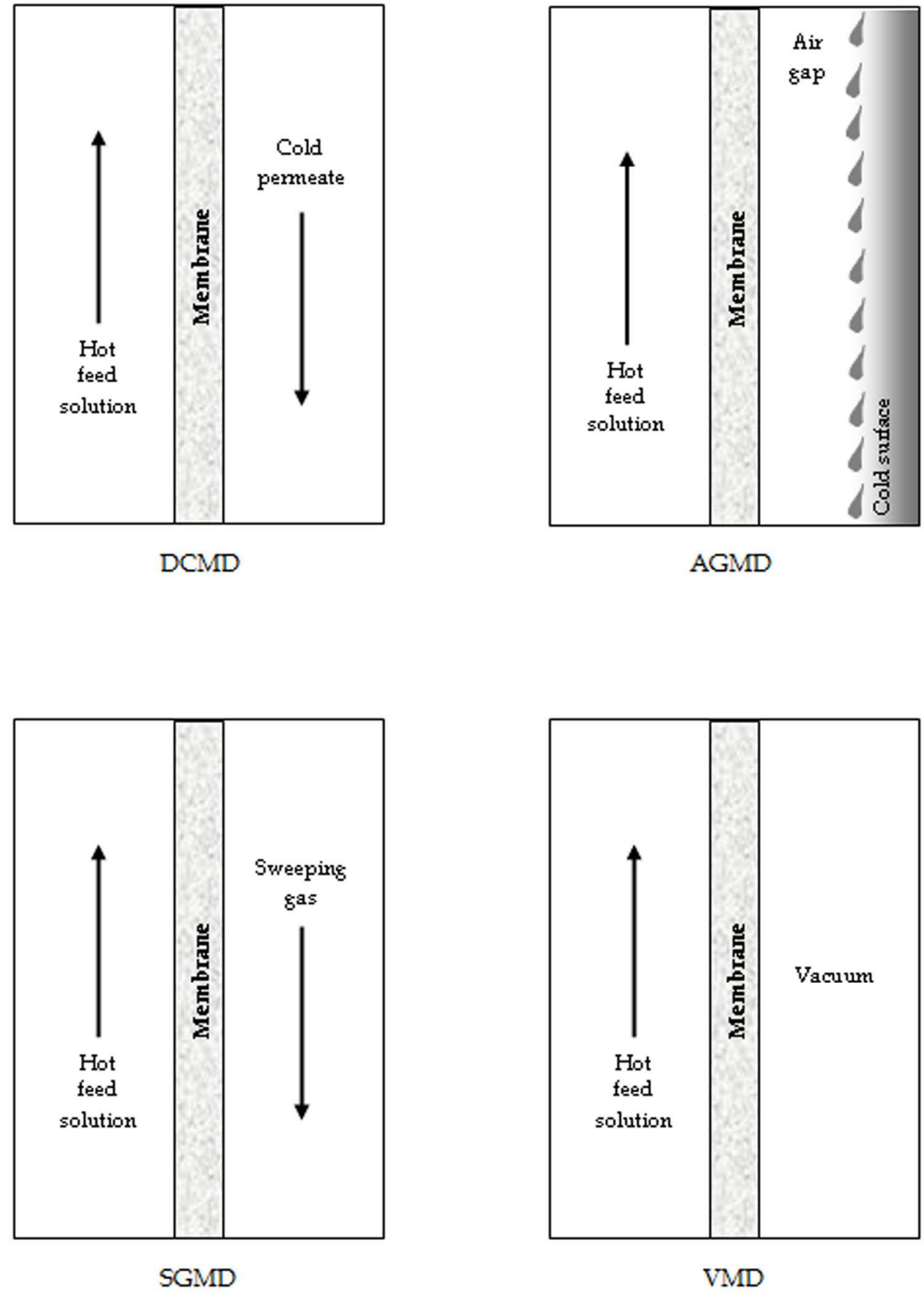

Fig. 1. Schematic representation of MD configurations 
convenience to set up in laboratory. However, direct contact of the membrane with the cooling side and poor conductivity of the polymeric material results heat losses throughout the membrane. Therefore, in DCMD the thermal efficiency which is defined as the fraction of heat energy used only for evaporation, is relatively smaller than the other three configurations.

2. In air gap membrane distillation (AGMD), water vapour is condensed on a cold surface that has been separated from the membrane via an air gap. The heat losses are reduced in this configuration by addition of a stagnant air gap between membrane and condensation surface.

3. In sweeping gas membrane distillation (SGMD), a cold inert gas is used in permeate side for sweeping and carrying the vapour molecules to outside the membrane module where the condensation takes place. Despite the advantages of a relatively low conductive heat loss with a reduced mass transfer resistance, due to the operational costs of the external condensation system, SGMD is the least used configuration.

4. In vacuum membrane distillation (VMD), the driving force is maintained by applying vacuum at the permeate side. The applied vacuum pressure is lower than the equilibrium vapour pressure. Therefore, condensation takes place outside of the membrane module.

Each of the MD configurations has its own advantages and disadvantages for a given application.

\section{Osmotic distillation}

Osmotic distillation (OD) is a non-thermal membrane distillation variant, in which a microporous hydrophobic membrane separates two aqueous solutions at different solute concentrations. The OD process can be operated at atmospheric pressure and ambient temperature. The driving force is the vapour pressure gradient across the membrane which is obtained by using a hypertonic salt solution on permeate side. The hydrophobic nature of the membrane prevents penetration of the pores by aqueous solutions, creating vapour/liquid interfaces at the entrance of the pores. Under these conditions, a net water flux from the high vapour pressure side to the low one occurs resulting in the concentration of feed and dilution of hypertonic salt solution. The water transport through the membrane can be summarized in three steps: (1) evaporation of water at the dilute vapour-liquid interface; (2) diffusional or convective vapour transport through the membrane pore; (3) condensation of water vapour at the membrane/brine interface (Jiao et al., 2004; Peinemann et al., 2010). In the literature the OD technique is also termed as isothermal membrane distillation, osmotic membrane distillation, osmotic evaporation and gas membrane extraction (Gryta, 2005b).

The basic requirements of osmotic agent are to be non-volatile, to have high osmotic activity in order to maintain a lower vapour pressure and to maximize the driving force and to be thermally stable to allow reconcentration of diluted stripping solution by evaporation. Other factors that should be taken into consideration are solubility, toxicity, corrosivity and cost. Although $\mathrm{NaCl}$ or $\mathrm{CaCl}_{2}$ have chosen as osmotic agent in most of the reported studies, both of these salts have the disadvantage of being corrosive to ferrous alloys (Celere \& Gostoli, 2004; Shin \& Johnson, 2007). $\mathrm{MgCl}_{2}, \mathrm{MgSO}_{4}, \mathrm{~K}_{2} \mathrm{HPO}_{4}$, and $\mathrm{KH}_{2} \mathrm{PO}_{4}$ are some other commonly used osmotic agents in OD. Potassium salts of ortho- and pyrophosphoric acid 
offer several advantages, including low-equivalent weight, high water solubility, steep positive temperature coefficients of solubility and safety in foods and pharmaceuticals (Jiao et al., 2004; Nagaraj et al., 2006a; Shin \& Johnson, 2007)

\section{Membrane characteristics}

The selection of the membrane is the most crucial factor in MD separation performance. As stated earlier, the membrane used for MD process must be hydrophobic and porous. There are various types of membranes meeting these expectations; however the efficiency of a given MD application depends largely on additional factors such as resistance to mass transfer, thermal stability, thermal conductivity, wetting phenomena and module characterization. Membrane and module related characteristics affecting selection of the appropriate membrane are summarized in this section.

\subsection{Membrane materials}

A large variety of membranes including both polymeric and inorganic membranes of hydrophobic nature can be used in MD process; however polymeric membranes have attracted much more attention due to their possibility to modulate the intrinsic properties. Polytetrafluoroethylene (PTFE), polypropylene (PP) and polyvinylidenefluoride (PVDF) are the most commonly used polymeric membranes due to their low surface tension values (Table 1). Hydrophobic porous membranes can be prepared by different techniques like sintering, stretching, phase inversion or thermally induced phase separation depending on the properties of the materials to be used. The useful materials should be selected according to criteria that include compatibility with the liquids involved, cost, ease of fabrication and assembly, useful operating temperatures, and thermal conductivity (Li et al., 2008; Liu et al., 2011). Among them, PTFE membranes are the most hydrophobic ones showing outstanding thermal stability and chemical resistance properties (they are low soluble in practically all common solvents). The main disadvantage of PTFE membranes is the difficulty of processing. PTFE membranes are generally prepared by sintering or stretching. PP exhibits

\begin{tabular}{|l|c|}
\hline \multicolumn{1}{|c|}{ Polymer } & $\begin{array}{c}\text { Surface tension } \\
\text { (Dynes/cm) }\end{array}$ \\
\hline Polytetrafluoroethylene (PTFE) & 19 \\
Polyvinylidenefluoride (PVDF) & 25 \\
Polypropylene (PP) & 29 \\
Polyethylene (PE) & 31 \\
Polypropylene (PP) & 34 \\
Polyvinyl alcohol (PVA) & 37 \\
Polysulfone (PS) & 41 \\
Polycarbonate (PC) & 45 \\
Polyurethane (PU) & 45 \\
\hline
\end{tabular}

Table 1. Critical surface tension values of some polymers (Adapted from Oliver, 2004; Pabby et al., 2009) 
excellent solvent resistant properties and high crystallinity. PP membranes are generally manufactured by stretching and thermal phase inversion. PVDF membranes exhibit good thermal and chemical resistance; however this polymer easily dissolves at room temperature in a variety of solvents including dimethylformamide (DMF) and triethylphosphate (TEP). PVDF membranes are generally prepared by phase inversion (Curcio and Drioli, 2005).

There are some additional criteria that should be taken into consideration for selection of the appropriate membrane for a given MD application such as pore size, tortuosity, porosity, membrane thickness and thermal conductivity. The relationship between the transmembrane flux and the different membrane characteristic related parameters is given by (Lawson \& Lloyd, 1997)

$$
N \alpha \frac{<r^{\alpha}>\varepsilon}{\tau \delta}
$$

where $N$ is the molar flux, $\langle r a\rangle$ is the mean pore size of the membrane pores where $a$ equals 1 for Knudsen diffusion and equals 2 for viscous flux, $\varepsilon$ is the membrane porosity, $\tau$ is the membrane tortousity and $\delta$ is the membrane thickness.

Membrane pore size: Membranes with pore sizes ranging from $10 \mathrm{~nm}$ to $1 \mu \mathrm{m}$ can be used in MD (Pabby et al., 2009). The permeate flux increases with the increase in pore size as determined by Knudsen model. However, in order to avoid wettability, small pore size should be choosen (El-Bourawi et al., 2006; Khayet, 2011). Thus, an optimum value for pore size has to be determined for each MD application depending on the type of the feed solution.

Membrane porosity: Membrane porosity is determined as the ratio between the volume of the pores and the total volume of the membrane. Evaporation surface area increases with the increase in porosity level of the membrane, resulting in higher permeate fluxes (Huo et al., 2011; Susanto, 2011). Membrane porosity also affects the amount of heat loss by conduction (Lawson \& Lloyd, 1996b):

$$
\begin{gathered}
Q_{m}=\mathrm{h}_{m} \Delta T_{m} \\
h_{m}=\varepsilon h_{m g}+(1-\varepsilon) h_{m s}
\end{gathered}
$$

where $\varepsilon$ is the membrane porosity, $h_{m g}$ is the conductive heat transfer coefficient of the gases entrapped in the membrane pores; $h_{m s}$ is the conductive heat transfer coefficient of the hydrophobic membrane material.

Conductive heat loss can be reduced by increasing porosity of the membrane, since $h_{m g}$ is generally an order of magnitude smaller than $h_{m s}$. In general, the porosity of the membranes used in MD operations lines in the range of $65 \%-85 \%$.

Pore tortuosity: Tortuosity is the average length of the pores compared to membrane thickness. The membrane pores do not go straight across the membrane and the diffusing molecules must move along tortuous paths, leading a decrease in MD flux. Therefore, permeate flux increases with the decrease in tortuosity. It must be pointed out that this value is frequently used as a correction factor for prediction of transmembrane flux due to 
the difficulties in measuring its real value for the membranes used in MD. In general a value of 2 is frequently assumed for tortuosity factor. (El-Bourawi et al., 2006; Khayet et al., 2004a; Phattaranawik et al., 2003a)

Membrane thickness: Permeate flux is inversely proportional to the membrane thickness in MD. Therefore, membrane must be as thin as possible to achieve high permeate flux. Thickness also plays an important role in the amount of conductive heat loss though the membrane. In order to reduce heat resistances, it should be as thick as possible leading to a conflict with the requirement of higher permeate flux. Hence membrane thickness should be optimized in order to obtain optimum permeate flux and heat efficiency. The optimum thickness for MD has been estimated within the range of 30-60 $\mu \mathrm{m}$ (Lagana et al., 2000).

Pore size distribution: Pore size distribution affects uniformity of vapour permeation mechanism. In general, uniform pore size is preferable rather than distributed pore size (Susanto, 2011).

Thermal conductivity: Thermal conductivity of the membrane should be small in order to reduce the heat loss through the membrane from feed to the permeate side. Conductive heat loss is inversely proportional to the membrane thickness. However selection of a thicker membrane decreases both the flux and permeability. One promising approach may be selection of a membrane with higher porosity since thermal conductivity of polymer membrane is significantly higher than thermal conductivity of water vapour in the membrane pores (Khayet et al., 2006). The thermal conductivities of polymers used in MD generally varies in the range of $0.15-0.45 \mathrm{~W} \mathrm{~m}^{-1} \mathrm{~K}^{-1}$ depending upon temperature and the degree of crystallinity (Alklaibi \& Lior, 2005).

Table 2 summarizes the commercial membranes commonly used by various researchers up to date together with their principal characteristics. In fact, there is a lack of commercially available MD units and most of the MD researches use modules actually designed for other membrane operations (i.e. microfiltration) rather than MD. Design of novel membranes fabricated especially for MD purposes have been recommended by MD investigators since commercially available membranes does not meet all the requirements listed above. Novel hydrophobic membranes for MD applications can be manufactured either by hydrophobic polymers or by surface modification of hydrophilic membranes. Various surface modification applications including coating, grafting and plasma polymerization (Brodard et al., 2003; Bryjak et al., 2000; Chanachai et al., 2010; Huo et al., 2010; Kong et al., 1992; Krajewski et al., 2006; Lai et al., 2011; Li \& Sirkar, 2004; VargasGarcia et al., 2011; Wu et al., 1992; Yang et al., 2011b) have been attempted until now. However, there is very limited number of studies on the design of MD membranes (Khayet, 2011; Khayet et al., 2010; Phattaranawik et al., 2009; Wang et al., 2009; Yang et al., 2011a). Therefore, new generation of membranes promising required features should be developed for MD applications.

\subsection{Membrane modules}

Choice and arrangement of the membrane module in a MD application is based on economic considerations with the correct engineering parameters being employed. Plate and frame, spiral wound, tubular, capillary and hollow fiber membrane modules are commonly used by MD researchers. 


\begin{tabular}{|c|c|c|c|c|c|c|c|}
\hline $\begin{array}{c}\text { Membrane } \\
\text { module }\end{array}$ & Manufacturer & $\begin{array}{l}\text { Trade } \\
\text { name }\end{array}$ & Polymer & $\begin{array}{c}\text { Membrane } \\
\text { thickness } \\
(\mu \mathrm{m})\end{array}$ & $\begin{array}{c}\begin{array}{c}\text { Nominal } \\
\text { pore size } \\
(\mu \mathrm{m})\end{array} \\
\end{array}$ & $\begin{array}{c}\text { Porosity } \\
(\%)\end{array}$ & References \\
\hline \multicolumn{8}{|l|}{ Flat sheet } \\
\hline \multirow{5}{*}{\multicolumn{2}{|c|}{$\begin{array}{c}3 \mathrm{M} \\
\text { Corporation }\end{array}$}} & 3MA & PP & 91 & 0.29 & 66 & \multirow{5}{*}{$\begin{array}{l}\text { (Kim \& Lloyd, } \\
\text { 1991; Lawson et } \\
\text { al., 1995; Lawson } \\
\text { \& Lloyd, 1996a) }\end{array}$} \\
\hline & & $3 \mathrm{MB}$ & PP & 81 & 0.40 & 76 & \\
\hline & & $3 \mathrm{MC}$ & PP & 76 & 0.51 & 79 & \\
\hline & & $3 \mathrm{MD}$ & PP & 86 & 0.58 & 80 & \\
\hline & & $3 \mathrm{ME}$ & PP & 79 & 0.73 & 85 & \\
\hline \multirow{5}{*}{\multicolumn{2}{|c|}{ Gelman }} & TF1000 & PTFE/PP & 60 & 0.1 & 80 & \multirow{5}{*}{$\begin{array}{c}\text { (Khayet et al., } \\
\text { 2004b; Martinez- } \\
\text { Diez et al., 1998; } \\
\text { Martinez et al., } \\
\text { 2002; Rincon et } \\
\text { al., 1999; } \\
\text { Rodrigues et al., } \\
\text { 2004) }\end{array}$} \\
\hline & & $\mathrm{TF} 450$ & PTFE/PP & 60 & 0.45 & 80 & \\
\hline & & TF200 & PTFE/PP & 60 & 0.20 & 80 & \\
\hline & & TF 200 & PTFE/PP & 178 & 0.20 & 80 & \\
\hline & & TF 200 & PTFE/PP & 165 & 0.20 & 60 & \\
\hline \multirow{5}{*}{\multicolumn{2}{|c|}{ Milipore }} & Durapore & PVDF & 110 & 0.45 & 75 & \multirow{5}{*}{$\begin{array}{c}\text { (Banat \& } \\
\text { Simandl, 1999; } \\
\text { Ding et al., 2003; } \\
\text { Khayet et al., } \\
\text { 2004b; } \\
\text { Phattaranawik et } \\
\text { al., 2003b; } \\
\text { Phattaranawik et } \\
\text { al., 2001) }\end{array}$} \\
\hline & & Durapore & PVDF & 100 & 0.20 & 70 & \\
\hline & & GVHP & PVDF & 125 & 0.20 & 80 & \\
\hline & & GVHP & PVDF & 125 & 0.22 & 75 & \\
\hline & & HVHP & PVDF & 116 & 0.45 & 66 & \\
\hline \multicolumn{2}{|r|}{ Sartorious } & & PTFE & 70 & 0.20 & 70 & $\begin{array}{c}\text { (Phattaranawik } \\
\text { et al., 2003b; } \\
\text { Warczok et al., } \\
\text { 2007) }\end{array}$ \\
\hline \multirow{2}{*}{\multicolumn{2}{|c|}{ Gore }} & & PTFE & 64 & 0.20 & 90 & \multirow[b]{2}{*}{$\begin{array}{l}\text { (Garcia-Payo et } \\
\text { al., 2000; } \\
\text { Izquierdo-Gil et } \\
\text { al., 1999; } \\
\text { Phattaranawik et } \\
\text { al., 2003b) }\end{array}$} \\
\hline & & & PTFE & 77 & 0.45 & 89 & \\
\hline \multirow{4}{*}{\multicolumn{2}{|c|}{ Osmonics }} & & PP & 150 & 0.22 & 70 & \multirow[t]{4}{*}{ (Cath et al., 2004) } \\
\hline & & & PTFE & 175 & 0.22 & 70 & \\
\hline & & & PTFE & 175 & 0.45 & 70 & \\
\hline & & & PTFE & 175 & 1.0 & 70 & \\
\hline \multirow{2}{*}{\multicolumn{2}{|c|}{$\begin{array}{l}\text { Hoechst } \\
\text { Celanese }\end{array}$}} & $\begin{array}{c}\text { Celgard } \\
2400\end{array}$ & $\mathrm{PP}$ & 28 & 0.05 & 45 & \multirow{2}{*}{$\begin{array}{l}\text { (Barbe et al., } \\
\text { 2000; Mengual et } \\
\text { al., 1993) }\end{array}$} \\
\hline & & $\begin{array}{c}\text { Celgard } \\
2500\end{array}$ & PP & 25 & 0.02 & 38 & \\
\hline
\end{tabular}


Membrane Distillation: Principle, Advances,

\begin{tabular}{|c|c|c|c|c|c|c|c|}
\hline $\begin{array}{l}\text { Membrane } \\
\text { module }\end{array}$ & Manufacturer & $\begin{array}{l}\text { Trade } \\
\text { name }\end{array}$ & Polymer & $\begin{array}{c}\text { Membrane } \\
\text { thickness } \\
(\mu \mathrm{m})\end{array}$ & $\begin{array}{c}\text { Nominal } \\
\text { pore size } \\
(\mu \mathrm{m})\end{array}$ & \begin{tabular}{|c} 
Porosity \\
$(\%)$
\end{tabular} & References \\
\hline \multicolumn{8}{|l|}{ Flat sheet } \\
\hline & \multirow[t]{2}{*}{ Enka } & $\begin{array}{l}\text { Accurel } \\
\text { 1E-PP }\end{array}$ & $\mathrm{PP}$ & & 0.25 & 25 & \multirow[t]{2}{*}{$\begin{array}{l}\text { (Mengual et al., } \\
\text { 1993; Narayan et } \\
\text { al., 2002) }\end{array}$} \\
\hline & & $\begin{array}{l}\text { Accurel } \\
\text { 2E-PP }\end{array}$ & PP & & 0.48 & 90 & \\
\hline \multicolumn{8}{|l|}{ Capillary } \\
\hline & \multirow[t]{2}{*}{ Membrana } & $\begin{array}{l}\text { Accurel } \\
\text { S6/2 }\end{array}$ & $\mathrm{PP}$ & 450 & 0.20 & 73 & \multirow{2}{*}{$\begin{array}{c}\text { (Celere \& } \\
\text { Gostoli, 2004; } \\
\text { Gryta, 2007) }\end{array}$} \\
\hline & & $\begin{array}{c}\text { Accurel } \\
\text { Q3/2 }\end{array}$ & $\mathrm{PP}$ & 400 & 0.20 & 70 & \\
\hline & Self-designed & PP & 800 & 0.40 & 73 & & \multirow{3}{*}{$\begin{array}{c}\text { (Gryta et al., } \\
\text { 2000b) } \\
\text { (Bui et al., 2004) }\end{array}$} \\
\hline & \multirow[t]{2}{*}{ Memcor } & PV 375 & PVDF & 125 & 0.20 & 75 & \\
\hline & & PV 660 & PVDF & 170 & 0.20 & 64 & \\
\hline \multicolumn{8}{|l|}{$\begin{array}{l}\text { Hollow } \\
\text { fiber }\end{array}$} \\
\hline & \multirow{4}{*}{$\begin{array}{l}\text { Hoechst- } \\
\text { Celanese }\end{array}$} & \multirow{4}{*}{$\begin{array}{l}\text { Liqui-Cel }^{\circledR} \\
\text { Extra-Flow } \\
2.5 \times 8 \text { in }\end{array}$} & $\mathrm{PP}$ & 180 & & 40 & \multirow{4}{*}{$\begin{array}{l}\text { (Bailey et al., } \\
\text { 2000) }\end{array}$} \\
\hline & & & PP & 53 & 0.074 & 50 & \\
\hline & & & PP & 50 & 0.044 & 65 & \\
\hline & & & PP & 47 & 0.056 & 42 & \\
\hline
\end{tabular}

Table 2. List of commercial membranes commonly used by various MD researchers

In plate and frame modules, the membranes which are usually prepared as discs or flat sheets are placed between two plates. The feed solution flows through flat, rectangular channels. Packing densities for flat sheet membranes may be in the range of $100-400 \mathrm{~m}^{3 / \mathrm{m}^{2}}$ (Pabby et al., 2009). Polymeric flat sheet membranes are easy to prepare, handle, and mount. The same module can be used to test many different types of MD membranes. The membrane can be supported to enhance mechanical strength. Babu et al. (2008) used a plate and frame membrane module having a membrane area of $0.01 \mathrm{~m}^{2}$ for the concentration of pineapple and sweet lime juice. The module consists of a polyester mesh $(0.25 \mathrm{~mm})$ and a hydrophobic microporous polypropylene membrane (pore size $0.20 \mu \mathrm{m}$ and thickness 175 $\mu \mathrm{m})$ supported in between a viton gasket $(3.0 \mathrm{~mm})$ and two stainless steel frames. In spiral wound membranes, the membrane, feed and permeate channel spacers and the porous membrane support form an envelope which is rolled around a perforated central collection tube and inserted into an outer tubular pressure shell. The feed solution passes in axial direction through the feed channel across the membrane surface. The filtrate moves along 
the permeate channel and is collected in a perforated central collection tube. Spiral-wound modules have a packing density of $300-1000 \mathrm{~m}^{2} / \mathrm{m}^{3}$ depending on the channel height, which is greater than that of the plate and frame module (Pabby et al., 2009). However, the spiral-wound module is quite sensitive to fouling. Tubular, capillary or hollow fiber membrane modules are shell and tube type modules housing pressure-tight tubes. The support is not needed in this type of modules. The membranes are usually a permanent integral part of the module and are not easily replaced. Tubular membrane modules provide much higher membrane surface area to module volume ratio than plate and frame modules (Khayet, 2011). The diameter of membranes in tubular module varies within the range of 10$25 \mathrm{~mm}$. The packing density is around $300 \mathrm{~m}^{2} / \mathrm{m}^{3}$ (Pabby et al., 2009). These modules offer higher cross-flow velocities and large pressure drop and generally used for MD of high viscous liquids. The diameters of membranes in capillary modules typically vary between 0.2-3 mm with packing densities of about $600-1200 \mathrm{~m}^{2} / \mathrm{m}^{3}$ (Li et al., 2008) . The production costs are very low and membrane fouling can effectively be controlled by the proper feed flow and back-flushing of permeate in certain time intervals. The main disadvantage of the capillary membrane module is the requirement of low operating pressure (up to 4 bars). The inner diameters of hollow fiber membranes is around $50-500 \mu \mathrm{m}$ with very high packing densities of about $3000 \mathrm{~m}^{2} / \mathrm{m}^{3}$. Hollow fiber module has the highest packing density of all module types. Its production is very cost effective and hollow fiber membrane modules can be operated at pressures in excess of 100 bars (El-Bourawi et al., 2006). The main disadvantage of the hollow fiber membrane module is the difficult control of membrane fouling. Therefore, a proper pretreatment should be applied for separation of macromolecules. For example, in the case of fruit juice concentration by MD using a hollow fiber module, clarification is a crucial pretreatment step to enhance MD flux (Cassano \& Drioli, 2007; Onsekizoglu et al., 2010b).

\subsection{Contact angle}

The contact angle is a common measurement of the hydrophobic or hydrophilic behaviour of a material. It provides information about relative wettability of membranes. The contact angle is determined as the angle between the surface of the wetted solid and a line tangent to the curved surface of the drop at the point of three-phase contact (Figure 2). The value of contact angle is greater than $90^{\circ}$ when there is low affinity between liquid and solid; in case of water, the material is considered hydrophobic and is less than $90^{\circ}$ in the case of high affinity. Wetting occurs at $0^{\circ}$, when the liquid spreads onto the surface (Curcio et al., 2010; Curcio \& Drioli, 2005; Pabby et al., 2009). The wettability of a solid surface by a liquid decreases as the contact angle increases. Table 3 lists the contact angle values for few

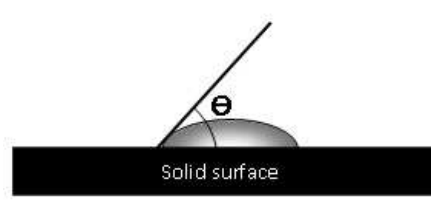

Hydrophilic

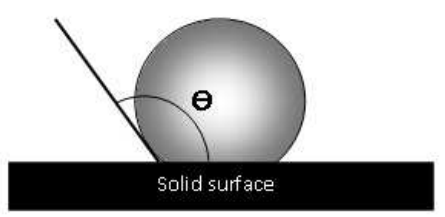

Hydrophobic

Fig. 2. Schematic representation of contact angle 


\begin{tabular}{|lc|}
\hline \multicolumn{1}{|c|}{ Material } & Contact Angle, $^{\circ}$ \\
\hline Ordinary glass & 20 \\
Polycarbonate & 70 \\
Polyamide & 69 \\
Polyethersulphone & 54 \\
Polyethylene & 96 \\
Polypropylene & 100 \\
PTFE & 123 \\
PVDF & 111 \\
Teflon & 112 \\
\hline
\end{tabular}

Table 3. Contact angle values of water on some materials at ambient temperature (Khayet \& Matsuura, 2011; Sigurdsson \& Shishoo, 1997)

different materials in water at ambient temperature. For example, the parameter measured on PTFE or PVDF membrane surface was $108^{\circ}$ or $107^{\circ}$, respectively (Curcio et al., 2010; Hwang et al., 2011; Tomaszewska, 2000).

\subsection{Liquid entry pressure and wetting phenomena}

The hydrophobic nature of membranes used in membrane distillation prevents penetration of the aqueous solutions into the pores unless a critical penetration pressure is exceeded, as stated earlier. Liquid entry pressure (LEP) is the minimum transmembrane hydrostatic pressure that must be applied before liquid solutions penetrate into the membrane pores. LEP can be calculated using the Laplace-Young equation (Burgoyne \& Vahdati, 2000; Lawson \& Lloyd, 1997).

$$
\Delta P=P_{F}-P_{D}-\frac{2 \beta \gamma_{L} \operatorname{Cos} \theta}{r_{m}}
$$

where $P_{F}$ and $P_{D}$ are the hydraulic pressure of the feed and distillate side, $\beta$ is the geometric pore coefficient (equals 1 for cylindrical pores), $\gamma_{L}$ is the surface tension of the liquid, $\theta$ is the contact angle and $r_{m}$ is the maximum pore size.

LEP depends on membrane characteristics and prevents wetting of the membrane pores during MD experiments. LEP increases with a decrease in maximum pore size at the surface and an increase at the hydrophobicity (i.e., large water contact angle) of the membrane material. The presence of strong surfactants or organic solvents can greatly reduce the liquid surface tension therefore causing membrane wetting. Therefore, care must be taken to prevent contamination of process solutions with detergents or other surfacting agents.

\section{Transport mechanisms and polarization phenomena}

\subsection{Theory of heat transfer}

Heat transfer in the MD includes three main steps:

i. Heat transfer through the feed side boundary layer 
ii. Heat transfer through the membrane

iii. Heat transfer through the permeate side boundary layer

Heat transfer through the feed side boundary layer Heat transfer from the feed solution to the membrane surface across the boundary layer in the feed side of the membrane module imposes a resistance to mass transfer since a large quantity of heat must be supplied to the surface of the membrane to vaporize the liquid. The temperature at the membrane surface is lower than the corresponding value at the bulk phase. This affects negatively the driving force for mass transfer. This phenomenon is called temperature polarization (El-Bourawi et al., 2006; Pabby et al., 2009; Qtaishat et al., 2008). Temperature polarization becomes more significant at higher feed temperatures (Burgoyne \& Vahdati, 2000; Lagana et al., 2000; Phattaranawik et al., 2003b).

The temperature polarization coefficient (TPC) is determined as the ratio of the transmembrane temperature to the bulk temperature difference:

$$
T P C=\frac{T_{f m}-T_{p m}}{T_{f b}-T_{p b}}
$$

where $T_{\mathrm{fm}}, T_{\mathrm{pm}}, T_{\mathrm{fb}}$ and $T_{\mathrm{pb}}$ are membrane surface temperatures and fluid bulk temperatures at the feed and permeate sides, respectively. A schematic diagram of the temperature polarization in MD is shown in Figure 3.

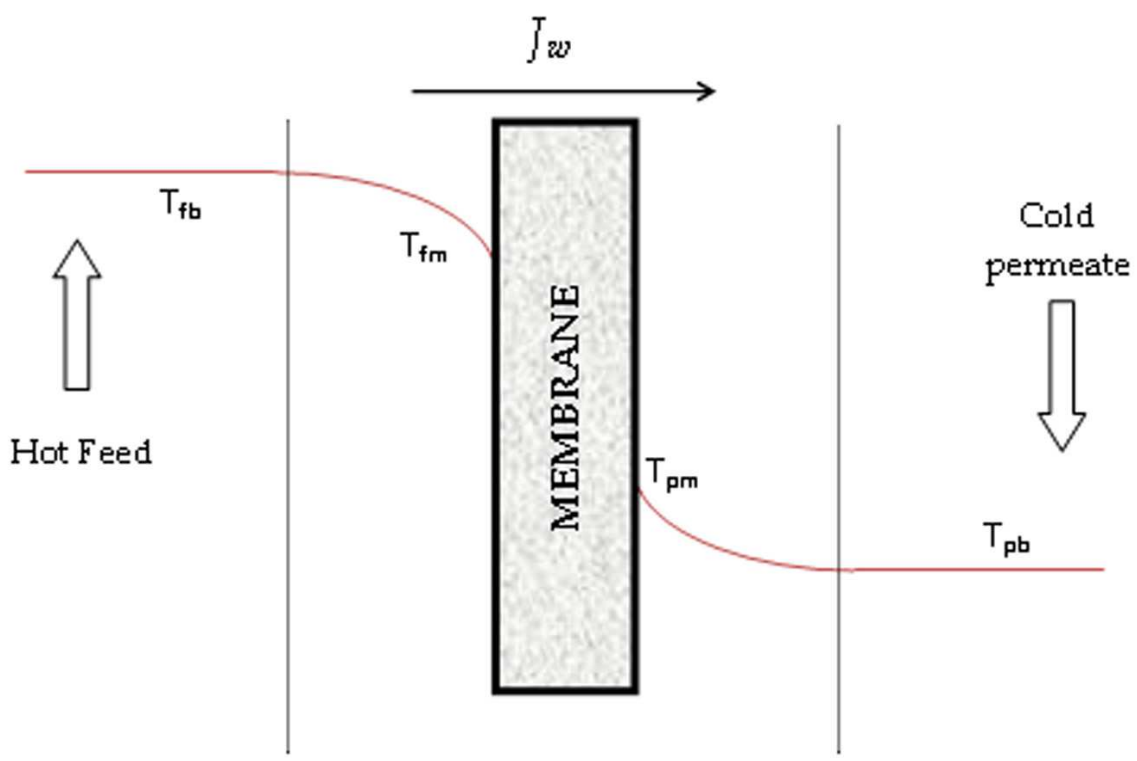

Fig. 3. Schematic diagram of temperature polarization in MD. $T_{\mathrm{fm}}, T_{\mathrm{pm}}, T_{\mathrm{fb}}$ and $T_{\mathrm{pb}}$ are membrane surface temperatures and fluid bulk temperatures at the feed and permeate sides, respectively.

Heat transfer through the feed side boundary layer can be calculated using: 


$$
Q_{f}=h_{f}\left(T_{f b}-T_{f m}\right)
$$

where $h_{f}$ is the heat transfer coefficient of the feed side boundary layer.

Heat transfer through the membrane: Heat transfer through the membrane appears as a combination of latent heat of vaporization $\left(Q_{V}\right)$ and conductive heat transfer across both the membrane matrix and the gas filled membrane pores $\left(Q_{C}\right)$. The corresponding values can be estimated by following equations:

$$
\begin{gathered}
Q_{V}=J \Delta H_{V} \\
Q_{C}=\left(\frac{k_{m}}{\delta}\right)\left(T_{f m}-T_{p m}\right)
\end{gathered}
$$

Therefore, the heat flux can be estimated by the following expression (El-Bourawi et al., 2006; Khayet \& Matsuura, 2011; Lawson \& Lloyd, 1997; Phattaranawik \& Jiraratananon, 2001; Schofield et al., 1990a)

$$
\begin{gathered}
Q_{m}=Q_{V}+Q_{C} \\
Q_{m}=\frac{k_{m}}{\delta}\left(T_{f m}-T_{p m}\right)+J \Delta H_{V}
\end{gathered}
$$

where $k_{m}$ is the thermal conductivity of the membrane, $\delta$ is the membrane thickness, $J$ is the permeate water vapour flux and $\Delta H_{V}$ is the latent heat of vaporization.

Various models have been proposed for estimation of $k_{m}$ in Equation [10]. Two of the most preferred ones are given below;

$$
\begin{aligned}
& k_{m}=\varepsilon k_{g}+(1-\varepsilon) k_{s} \\
& k_{m}=\left[\frac{\varepsilon}{k_{g}}+\frac{(1-\varepsilon)}{k_{s}}\right]^{-1}
\end{aligned}
$$

Heat transfer through the permeate side boundary layer: Heat transfer from the membrane surface to the bulk permeate side across the boundary layer is also related with the temperature polarization phenomenon. The temperature of membrane surface at the permeate side is higher than that of bulk permeate due to the temperature polarization effect.

Heat transfer through the permeate side boundary layer is given as:

$$
Q_{p}=h_{p}\left(T_{p m}-T_{p b}\right)
$$

where $h_{p}$ is the heat transfer coefficient of the permeate side boundary layer.

Both feed and permeate side boundary layers are function of fluid properties and operating conditions, as well as the hydrodynamic conditions. There are some convenient approaches in the literature to reduce the temperature polarization effects like mixing thoroughly, working at 
high flow rates or using turbulence promoters (Cath et al., 2004; Chernyshov et al., 2005; ElBourawi et al., 2006; Lawson \& Lloyd, 1996a; Martinez \& Rodriguez-Maroto, 2006).

\subsection{Theory of mass transfer}

As mentioned above, the mass transfer in MD is driven by the vapour pressure gradient imposed between two sides of the membrane. Mass transfer in membrane distillation consists of three consecutive steps:

i. Evaporation of water at the liquid/gas interface on the membrane surface of the feed side

ii. Water vapour transfer through the membrane pores

iii. Condensation of water vapour at the gas/liquid interface on the membrane surface of the permeate side

The mass flux ( $J$ ) can be expressed as (Close \& Sorensen, 2010; Zhang et al., 2010):

$$
J=K \Delta P
$$

where $K$ is the overall mass transfer coefficient which is the reciprocal of an overall mass transfer resistance. This overall resistance is the sum of three individual resistances:

$$
K=\left[\frac{1}{K_{f}}+\frac{1}{K_{m}}+\frac{1}{K_{p}}\right]^{-1}
$$

where $K_{f}, K_{m}$ and $K_{p}$ are the mass transfer coefficients of feed layer, membrane and permeate layer, respectively.

Mass transfer trough feed side boundary layer: In membrane distillation, only water vapour transport is allowed due to the hydrophobic character of the membrane. Therefore the concentration of solute(s) in feed solution becomes higher at the liquid/gas interface than that at the bulk feed as mass transfer proceeds. This phenomenon is called concentration polarization and results in reduction of the transmembrane flux by depressing the driving force for water transport. Concentration polarization coefficient $(C P C)$ is determined as the ratio of the solute concentration at the membrane surface $\left(C_{f m}\right)$ to that at the bulk feed solution $\left(C_{f b}\right)$ :

$$
C P C=\frac{C_{f m}}{C_{f b}}
$$

The concentration gradient between the liquid/gas interface and the bulk feed results a diffusive transfer of solutes from the surface of the membrane to the bulk solution. At steady state, the rate of convective solute transfer to the membrane surface is balanced by diffusion of solute to the bulk feed.

The molar flux is expressed as follows (El-Bourawi et al., 2006; Khayet \& Matsuura, 2011):

$$
J=k_{s} \ln \left(\frac{C_{f m}}{C_{f b}}\right)
$$


where $k_{s}$ is the diffusive mass transfer coefficient through the boundary layer. Several empirical correlation of dimensionless numbers, namely, Sherwood $(S h)$, Reynolds $(R e)$, Schmidt $(\mathrm{Sc})$, Nusselt $(\mathrm{Nu})$ and Prandtl $(\mathrm{Pr})$ numbers can be used to estimate the value of $k_{s}$ depending on the hydrodynamics of the system:

$$
S h=\frac{k L}{D} \quad \operatorname{Re}=\frac{L u \rho}{\mu} \quad \mathrm{Sc}=\frac{\mu}{\rho D} \quad \mathrm{Nu}=\frac{h L}{k} \quad \operatorname{Pr}=\frac{\mu C_{P}}{k}
$$

where $L$ : characteristic length, $D$ : diffusion coefficient, $\rho$ : density, $\mu$ : viscosity, $u$ : feed velocity, $k$ : thermal conductivity, $C_{P}$ : specific heat, $h$ : boundary layer heat transfer coefficient (Babu et al., 2008).

In other membrane separation process such as microfiltration, ultrafiltration and reverse osmosis, concentration polarization is usually considered a major cause for flux decline (Agashichev, 2006; Morao et al., 2008; Song, 2010; Wang \& Tarabara, 2007; Zaamouche et al., 2009). On the other hand, it is agreed upon that concentration polarization is insignificant compared to temperature polarization in DCMD (Khayet \& Matsuura, 2011; Lagana et al., 2000; Martinez \& Rodriguez-Maroto, 2007).

It is worth pointing out that in osmotic distillation process, concentration polarization exists at each side of the membrane. During osmotic distillation, as mass transfer proceeds, solute concentration increases at the membrane surface due to evaporation of water vapour at the feed side. On the other hand, the solute concentration decreases due to the condensation of water vapour on the permeate side, giving rise to the difference in brine concentrations (Figure 4). The existence of concentration polarization layers at each side of the membrane

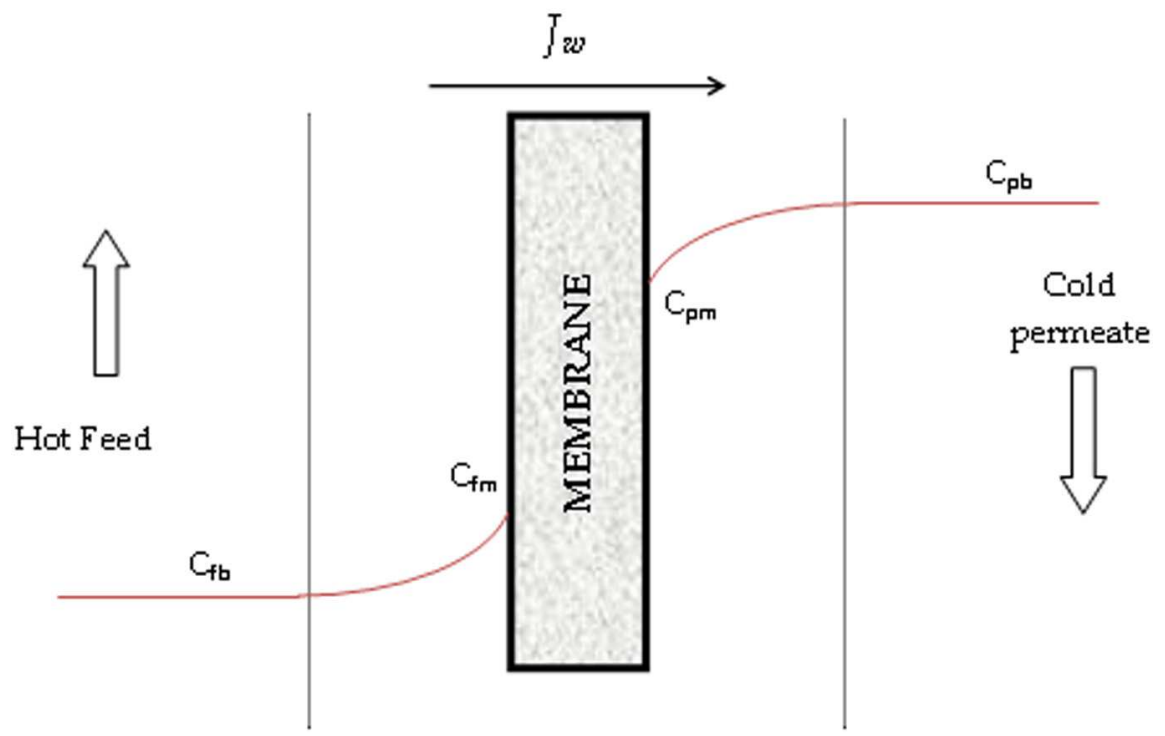

Fig. 4. Schematic diagram of concentration polarization in $\mathrm{MD} . \mathrm{C}_{\mathrm{fm}}, \mathrm{C}_{\mathrm{pm}}, \mathrm{C}_{\mathrm{fb}}$ and $\mathrm{C}_{\mathrm{pb}}$ are membrane surface and bulk solute concentrations at the feed and permeate sides, respectively. 
results in the reduction of driving force for water vapour transport leading a decrease in transmembrane flux (Babu et al., 2006; Babu et al., 2008; Nagaraj et al., 2006b).

Mass transfer through the membrane pores: The main mass transfer mechanisms through the membrane in MD are Knudsen diffusion and molecular diffusion (Figure 5). Knudsen diffusion model is responsible for mass transfer through the membrane pore if the mean free path of the water molecules is much greater than the pore size of the membrane and hence, the molecules tend to collide more frequently with the pore wall (Li et al., 2008; Nagaraj et al., 2006b; Pabby et al., 2009; Srisurichan et al., 2006).
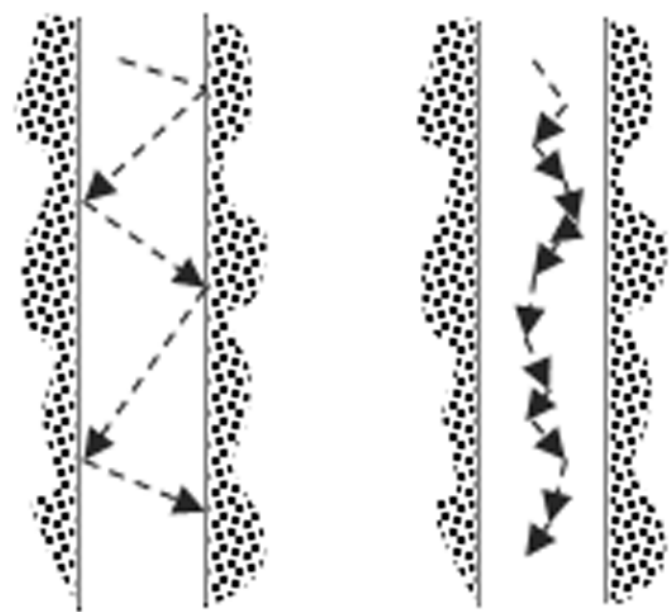

Fig. 5. Mass transfer mechanism involved in water vapour transport through membrane pores of MD module.

In this case, the membrane diffusion coefficient is calculated using equation:

$$
K_{m}=1.064 \frac{r \varepsilon}{\tau \delta}\left(\frac{M}{R T}\right)^{0.5}
$$

where $\varepsilon$ is the fractional void volume, $\delta$ is the membrane thickness, $\tau$ is the tortuosity, $M$ is the molecular weight of water, $R$ is the gas constant and $T$ is the absolute temperature.

On the other hand, when the pore size is relatively large, the molecule-molecule collisions are more frequent and molecular diffusion is responsible for mass transfer through the membrane pores (Khayet \& Matsuura, 2011).

$$
K_{m}=\frac{1}{Y_{\ln }} \frac{D \varepsilon}{\tau \delta} \frac{M}{R T}
$$

where $Y_{\ln }$ is the $\log$ mean of mole fraction of air and D is the diffusion coefficient.

Both models were successfully applied for predicting the mass transfer through the membrane in DCMD systems (Babu et al., 2006; Bandini \& Sarti, 1999; Chen et al., 2009; Lawson \& Lloyd, 1996b; Nagaraj et al., 2006b; Srisurichan et al., 2006). 


\section{Process parameters}

\section{Feed concentration}

Permeate flux decreases with an increase in feed concentration. This phenomenon can be attributed to the reduction of the driving force due to decrease of the vapour pressure of the feed solution and exponential increase of viscosity of the feed with increasing concentration. The contribution of concentration polarization effects is also known, nevertheless, this is very small in comparison with temperature polarization effects (Lagana et al., 2000; Pabby et al., 2009). As it is well known, MD can handle feed solutions at high concentrations without suffering the large drop in permeability observed in other pressure-driven membrane processes and can be preferentially employed whenever elevated permeate recovery factors or high retentate concentrations are requested (i.e. concentration of fruit juices) (Curcio \& Drioli, 2005; Li \& Sirkar, 2005; Schofield et al., 1990b).

\section{Feed temperature}

Various investigations have been carried out on the effect of the feed temperature on permeate flux in MD. In general, it is agreed upon that there is an exponential increase of the MD flux with the increase of the feed temperature. As the driving force for membrane distillation is the difference in vapour pressure across the membrane, the increase in temperature increases the vapour pressure of the feed solution, thus results an increase in the transmembrane vapour pressure difference.

It is worth quoting that working under high feed temperatures was offered by various MD researches, since the internal evaporation efficiency (the ratio of the heat that contributes to evaporation) and the total heat exchanged from the feed to the permeate side is high. Nevertheless, the increase in quality losses and formation of unfavorable compounds (i.e. hydroxymethyl furfural and furan) in fruit juices due to high operation temperatures restricts the temperature levels (Ciesarova \& Vranova, 2009; Crews \& Castle, 2007; Onsekizoglu et al., 2010b). Temperature polarization effect also increases with the increase in feed temperature (Moon et al., 2011).

\section{Feed flow rate \& stirring}

In MD, the increase in flow and/or stirring rate of feed increases the permeate flux. The shearing forces generated at high flow rate and/or stirring reduces the hydrodynamic boundary layer thickness and thus reduce polarization effects. Therefore, the temperature and concentration at the liquid-vapour interface becomes closer to the corresponding values at the bulk feed solution (Winter et al., 2011). Onsekizoglu et al. (2010a) studied the effects of various operating parameters on permeate flux and soluble solid content of apple juice during concentration through osmotic distillation (OD) and membrane distillation (MD) processes. They observed that the effect of feed flow rate on transmembrane flux was less than half of the influence of temperature difference across the membrane.

The effect of flow rate on MD flux becomes more noticeable at higher temperatures especially associated with higher temperature drop across the membrane (Walton et al., 2004). Consequently, higher productivity can be achieved by operating under a turbulent flow regime. On the other hand, the liquid entry pressure of feed solution (LEP) must be taken into account in order to avoid membrane pore wetting when optimizing feed flow rate (Hwang et al., 2011; Khayet et al., 2006). 


\section{Permeate temperature}

The increase in permeate temperature results in lower MD flux due to the decrease of the transmembrane vapour pressure difference as soon as the feed temperature kept constant. It is generally agreed upon that the temperature of cold water on the permeate side has smaller effect on the flux than that of the feed solution for the same temperature difference. This is because the vapour pressure increases exponentially with feed temperature (Alklaibi \& Lior, 2005; El-Bourawi et al., 2006).

\section{Permeate flow rate}

The increase in permeate flow and/or stirring rate reduces the temperature polarization effect. Consequently, the temperature at the gas/liquid interface approaches to the bulk temperature at the permeate side. This will tend to increase driving force across the membrane; resulting an increase in MD flux (Courel et al., 2000; Hongvaleerat et al., 2008). It is important to note that as the permeate used in the MD is distilled water and in the OD is hypertonic salt solution; the extent of the effect of flow rate is more prominent in the latter configuration. This is because of the contribution of concentration polarization effects on permeate side in OD.

\section{Flux enhancement approaches}

The MD process has some significant advantages over conventional processes, however beside the lack of commercially available MD modules, one of the major technical drawbacks for the use of MD in industrial applications is the low transmembrane flux in comparison with RO. Numerous studies have been performed to reduce polarization effects and to enhance transmembrane flux including cooperation of MD with other membrane processes as well as novel MD module design approaches. Some of mentioned attempts are discussed here.

The combination of MD with other membrane systems such as RO, UF, MF, NF and OD have been well-studied by MD researchers in order to improve transmembrane flux, recovery factors and final product quality (Cabral et al., 2011; Calabro \& Drioli, 1997; Cath et al., 2005; Cisse et al., 2011; Conidi et al., 2011; Gomes et al., 2011; Gryta, 2005b; Hogan et al., 1998; Mericq et al., 2009; Wang et al., 2011). Each process is unique and contributes particular advantages to the integrated system design.

UF is a powerful method for removing natural polymers (polysaccharides, proteins) that could increase the viscosity of the feed stream through the MD process. For example, pretreatment of grape juice by UF has been shown to result in an increased flux during subsequent concentration of permeate by OD. The flux increase has been attributed to the reduction in the viscosity of the concentrated juice membrane boundary layer due to protein removal (Bailey et al., 2000). Lukanin et al. (2003) have evaluated the use of an enzymatic pretreatment step before UF of apple juices. The protein level which tend to deposit on the hydrophobic surface during subsequent OD process, have been shown to decrease significantly. Such a deposition improves membrane wetting and can eventually result in a convective flow of liquid through the membrane, which is not allowable in the MD process. Onsekizoglu et al. (2010b) have proposed the use of membrane processes for the production of clarified apple juice concentrate. The efficiency of UF was improved by an additional enzymatic pretreatment and 
flocculation step using fining agents such as gelatine and bentonite. Hongvaleerat et al. (2008) obtained flux values of about $7-10 \mathrm{~kg} / \mathrm{m}^{2} \mathrm{~h}$ in pineapple juice concentrate production by OD which were higher than those obtained with single-strength juice.

$\mathrm{RO}$ or forward osmosis (FO) processes have been proposed as a pre-concentration step before OD or MD promising reduction of processing costs. High quality fruit juice concentrates can be produced economically in this manner. Therefore, an integrated process involving preconcentration of the feed by RO followed by further concentration by OD or MD should yield a high-solids product concentrate of quality comparable to that achieved by OD alone but at significant reduction in processing cost (Martinetti et al., 2009; Nayak \& Rastogi, 2010; Wang et al., 2011). The combination of RO and OD processes was evaluated by Cabra et al. (2011) for concentration of Acerola juice, by Kozak et al. (2009) for concentration of Black currant juice, by Galaverna et al. (2008) for concentration of blood orange juice, by Cassano et al. (2003) for concentration of citrus and carrot juices. It is worth mentioning that in all the previously mentioned studies, a clarification pretreatment step (i.e. ultrafiltration of microfiltration) is involved in order to improve both $\mathrm{RO}$ and OD flux.

Criscuoli \& Drioli (1999) presented a detailed energetic and exergetic analysis of both ROMD and NF-RO-MD integrated systems. They observed an improvement in the performance of the integrated system by introducing NF as water pretreatment for the ROMD system with almost the same energy.

The coupled operation of MD and OD processes is another promising approach to improve transmembrane flux. In this case, osmotic solution is cooled and the feed solution is slightly heated in order to provide additional driving force. Belafi-Bako \& Koroknai (2006) compared $\mathrm{MD}$, OD and coupled operation of OD and MD in terms of flux and final soluble solid concentration in sucrose model solutions and apple juice. Higher water flux and SSC values were achieved with coupled operation confirming an increase in driving force. More recently, Onsekizoglu (2011), have proposed the use of a coupled membrane process capable of concentrating pomegranate juice under very mild conditions. The pomegranate juice was clarified by ultrafiltration in a cross-flow membrane filtration unit (MWCO: $100 \mathrm{kDa}$ ). The clarified juice then concentrated by coupled operation of OD and MD, in which the feed solution is gently heated $\left(30.0 \pm 2.0^{\circ} \mathrm{C}\right)$ and the osmotic solution $\left(\mathrm{CaCl}_{2} \cdot \mathrm{H}_{2} \mathrm{O}\right)$ is slightly cooled $\left(10.0 \pm 1.0^{\circ} \mathrm{C}\right)$. The final step yielded a concentration of the clarified juice (with an initial total soluble solid content of (TSS) $17^{\circ}$ Brix) up to $60-62^{\circ}$ Brix. The experiments have proven that the driving forces were added in coupled operation, which resulted in enhanced water flux during the operation, thus the coupled process was proposed to be more effective.

Several strategies for reducing temperature polarization through membrane arrangement in MD have been proposed. Some authors have considered the use of spacer-filled channels (Chernyshov et al., 2003; Cipollina et al., 2011; Phattaranawik et al., 2001; Teoh et al., 2008; Wang, 2011). The spacers can improve the flow characteristics at the membrane surface and by promoting regions of turbulence due to the formation of eddies and wakes. Therefore, the temperature polarization can be reduced by improved boundary layer heat transfer. Various surface modification techniques including coating, grafting and plasma polymerization to reduce temperature polarization effect though improvement of membrane surface characteristics have been employed. For example, a novel hollow fiber membrane was proposed by Li \& Sirkar (2005) which were commercial porous PP hollow fibres coated with a variety of ultrathin microporous silicone-fluoropolymer layer on surface 
by plasma polymerization. The coated fibres were arranged in a rectangular cross-flow module design, permitting the hot feed solution to flow over the outside surface of the fibres with a higher Reynolds value. Therefore, reduced temperature polarization inducing higher permeate fluxes have been reported. The reason for applying the coating layer was to provide an additional porous layer having higher hydrophobicity than PP, which itself is one of the polymeric materials with very low surface energy (Li et al., 2008). In recent years, a novel multiple-layered composite membrane have been proposed by Qtaishat et al. (2009) comprising a thin hydrophobic microporous layer and a thin hydrophilic layer. The hydrophobic side of the membrane was maintained adjacent to the hot feed, whereas the hydrophilic layer of the membrane was kept adjacent to cold water, which penetrates into the pores of the hydrophilic layer. Such membranes were found to be promising as they combine the low resistance to mass flux, achieved by the diminution of the water vapour transport path length through the hydrophobic thin top layer and a low conductive heat loss through the membrane, obtained by using a thicker hydrophilic sublayer.

\section{Long-term performance}

\section{Membrane fouling \& Cleaning procedures}

Membrane fouling refers to the loss of membrane performance due to deposition of suspended or dissolved substances on the membrane surface and/or within its pores. There are several types of fouling in the membrane systems including inorganic fouling or scaling, particulate/colloidal fouling, organic fouling and biological fouling (biofouling) (Gryta, 2008). Inorganic fouling or scaling is caused by the accumulation of inorganic precipitates, such as calcium salts $\left(\mathrm{CaCO}_{3}, \mathrm{CaSO}_{4}\right)$, and magnesium carbonates on membrane surface or within pore structure. Precipitates are formed when the concentration of these sparingly soluble salts exceeds their saturation concentrations. Particulate/colloidal fouling is mainly associated with accumulation of biologically inert particles and colloids on the membrane surface. Organic fouling is related with the deposition or adsorption of organic matters on the pores of the membrane surface. Microbial fouling however is formed due to the formation of biofilms on membrane surfaces. Such films (bacterial, algal, or fungal) grow and release biopolymers (polysaccharides, proteins, and amino sugars) as a result of microbial activity (Pabby et al., 2009).

Even though the general agreement is that the fouling phenomena is significantly lower than those encountered in other pressure-driven membrane separation processes, it is one of the major drawbacks in membrane distillation (Gryta, 2005b). The extensive research on membrane fouling has revealed that the efficiency of MD installation can be reduced by more than 50 percent after $50-100 \mathrm{~h}$ of process operation due to the presence of fouling effects. In fact, all of the known types of fouling have been determined to occur practically in MD operations (Gryta, 2008).

Kullab \& Martin (2011) pointed out that fouling and scaling may result pore clogging in MD membranes, leading to a decrease in effective membrane area, and therefore the permeate flux. Moreover, the flow channel area may be reduced resulting higher temperature polarization due to the pressure drop across the membrane. The increased deposition of the foulant species at the membrane surface would eventually lead to an increase in the pressure drop to levels that the hydrostatic pressure may exceed the LEP of the feed or 
permeate solution into the membrane pores. Therefore the hydrophobic surface of membrane can be partially wetted due to very small nature of the flow channels in MD modules (especially in hollow fiber membrane modules) (El-Bourawi et al., 2006).

It should be emphasized here that although the importance of understanding the fouling phenomena in MD has been pointed out, very few studies have paid attention to long term performance. Most of the performed fouling studies so far examined fouling and scaling in seawater desalination or wastewater treatment applications.

Gryta (2005a) presented the results of the over 3 years' time research on the direct contact membrane distillation applied for production of the demineralised water using commercial capillary PP membranes. It was found that the membrane was thermally stable, maintaining its morphology and its good separation characteristics throughout the 3 years of DCMD operation. When using permeate of the RO system as DCMD feed solution, membrane pore wetting was not observed; and the DCMD flux was found to be similar to the initial permeate flux. However, precipitation of $\mathrm{CaCO}_{3}$ on the membrane surface was observed when tap water was used directly as a feed. A partial wetting of the membrane was found in this case resulting in a decrease of the permeate flux from 700 to $550 \mathrm{~L} / \mathrm{m}^{2} \mathrm{day}$. However, the formed deposit was removed every $40-80 \mathrm{~h}$ by rinsing the module with a $2-5 \mathrm{wt} \% \mathrm{HCl}$ solution, permitting the recovery of the initial process efficiency. On the other hand, authors reported that a multiple repetition of this operation resulted in a gradual decline of the maximum flux of permeate.

Ding et al. (2008) investigated the fouling resistance in concentrating traditional Chinese medicine (TCM) extract by DCMD. The observed permeate flux decline was attributed to membrane fouling introducing additional thermal resistance in the boundary layer. No considerable membrane wetting due to TCM deposition on the membrane surface was detected.

The membranes used in MD require regular periodic membrane cleaning to remove membrane fouling and keep the permeability loss within a given range. Durham \& Nguyen (1994) evaluated the effectiveness of several cleaning agents for OD membranes fouled by tomato paste. The microporous PTFE and cross-linked acrylic-fluoroethane copolymer membranes were used in the study. The cleaning regime was determined by the membrane surface tension. The most effective cleaner for membranes with a surface tension greater than $23 \mathrm{mN} / \mathrm{m}$ was determined as $1 \% \mathrm{NaOH}$; however, hydrophobic integrity of these membranes was destroyed during repeated fouling/cleaning trials. On the other hand, P3 Ultrasil 56 was the most effective one for membranes with a surface tension less than 23 $\mathrm{mN} / \mathrm{m}$. Water vapour flux was maintained and no salt leakage during repeated fouling/cleaning trials were determined.

Bubbling seems to be an obvious strategy to induce flow and improve shear stress at the membrane surface to control polarization and fouling. Ding et al. (2011) successfully employed the intermittent gas bubbling method to reduce fouling layer formed in concentrating TCM extract through DCMD. To limit membrane fouling or flux decline during concentrating process, intermittent gas bubbling was introduced to the feed side of membrane module. It was confirmed by experimental results that membrane fouling was effectively controlled in the way of removing deposited foulants from membrane surface by created two phase flow. 
As can be concluded from the expressed results, there is a lack of data and understanding in fouling phenomena in MD especially in the food processing field. However, the risk of fouling and wetting of membrane pores compromises the durability of the membranes limiting their applications in food industry. The long term MD performance needs to be extensively studied so as to make the MD process more challenging in food industry.

\section{Applications in food industry}

The main food-related applications of membrane distillation are the desalination and production of high purity water from brackish water and seawater. The major advantage of MD in desalination is the ability to achieve high rejection factors which cannot be accomplished by $\mathrm{RO}$ at high permeate fluxes. Production of high purity water is wellestablished with rejection factors of almost $100 \%$ of non-volatile compounds (Khayet \& Matsuura, 2011). The MD process has been successfully studied for purification of waste waters of pharmaceutical (Ding et al., 2011) and textile (Criscuoli et al., 2008) industries as well as underground waters contaminated with heavy metals (Zolotarev et al., 1994) and sulfuric acid solutions (Tomaszewska, 2000). Very recently, the feasibility of applying membrane distillation process for recovering potable water from arsenic, uranium and fluoride contaminated brackish waters has been proposed (Yarlagadda et al., 2011). A high quality permeate with dissolved solids concentrations less than $20 \mathrm{ppm}$ ( $>99 \%$ rejection of salts) along with arsenic, fluoride and uranium contaminant reductions in the range of 96.599.9\% were reported. Ke He et al. (2011) reported a flux value of $14.36 \mathrm{~L} / \mathrm{m}^{2} \mathrm{~h}$ over one month DCMD operation of sea water at the following conditions: hot side inlet temperature of $60{ }^{\circ} \mathrm{C}$, cold side inlet temperature of $20^{\circ} \mathrm{C}$, and hot and cold side flow rate of $0.6 \mathrm{~L} / \mathrm{min}$ for PTFE pore size $0.22 \mu \mathrm{m}$ membranes. The electrical conductivity values of permeate were determined below $8 \mu \mathrm{S} / \mathrm{cm}$. Gryta (2010) evaluated the desalination of water containing up to $12 \mathrm{~g} / \mathrm{L}$ of soluble salts MD for $250 \mathrm{~h}$ by using PP membranes. Electrical conductivity values of produced water were in the range of 3.4-4.1 $\mathrm{\mu S} / \mathrm{cm}$ despite a ten-fold increase of salt concentration. The permeate flux during MD process lasting $250 \mathrm{~h}$ decreased slightly from 543 to $498 \mathrm{~L} / \mathrm{m}^{2} \mathrm{~h}$. Thermal water pretreatment was used to prevent scaling which was formed due to decomposition of bicarbonates dissolved in water. On the other hand, the operation was found to be beneficial only for underground waters with high hardness.

One of the main advantages of MD in water purification is the lower energy consumption. Like any other distillation process MD also requires energy for evaporation of water, as stated earlier. However, MD process can effectively operate at low temperatures, which makes it possible to utilize low-grade waste and/or alternative energy sources, such as solar and geothermal energy.

MD and OD are proposed as very challenging technologies for concentration of fruit juice allowing to overcome the drawbacks of conventional thermal evaporation encountered by application of high temperatures (Ali et al., 2003; Bui \& Nguyen, 2005; Cisse et al., 2005; Pabby et al., 2009; Shaw et al., 2002; Vaillant et al., 2001). The preliminary study of effective concentration of orange juice by MD was presented by Calabro et al. (1994) using a microporous PVDF membrane. Alves \& Coelhoso (2006) compared MD and OD in terms of water flux and aroma retention in model orange juice. A higher retention per amount of water removal was observed with OD together with higher flux values. Very recently, Jorgensen et al. (2011) evaluated the potential of SGMD and VMD configurations for 
recovery of black currant and cherry juice aroma compounds. The influence of the sweeping gas flow rate (SGMD only), feed temperature and feed flow rate on the permeate flux and the concentrations factors of 12 selected aroma compounds were examined on an aroma model solution and on black currant juice in a laboratory scale set-up. At $45^{\circ} \mathrm{C}$ the most volatile and hydrophobic aroma compounds was obtained with the highest concentration factors: 12.1-9.3 (black currant juice) and 17.2-12.8 (model solution). A volume reduction of $13.7 \%$ (vol.\%) at $45{ }^{\circ} \mathrm{C}, 400 \mathrm{~L} / \mathrm{h}$, resulted in an aroma recovery of $73-84 \mathrm{vol} . \%$ for the most volatile compounds in black currant juice.

In concentration of fruit juices containing oily constituents (such as limonene in orange juice), membrane wetting may occur due to high affinity of hydrophobic membrane material with such compounds. Coating of membrane with hydrophilic polymers such as polyvinyl alcohol (PVA) (Mansouri \& Fane, 1999) and alginate (Xu et al., 2004) has been proposed to overcome this problem. Recently, Chanachai et al. (2010) studied the coating of hydrophobic membrane PVDF with chitosan, a highly hydrophilic polymer, for protection against wetting by oils from fruit juice. The results indicated that the coated membrane well protected the membrane against wetting-out and could maintain stable flux. Coated membranes used to concentrate the oil solution (limonene $2 \%, \mathrm{v} / \mathrm{v}$ ) for $5 \mathrm{~h}$ were not wetted out during flux measurement and no visual damage was observed indicating the stability on the base membrane.

It has been well-established that the combination of MD with other membrane technologies offers important benefits over stand alone use of MD in the concentration of various types of juices including grape juice (Rektor et al., 2007), pineapple juice (Hongvaleerat et al., 2008), kiwi fruit juice (Cassano \& Drioli, 2007), camu-camu juice (Rodrigues et al., 2004), sugarcane juice (Nene et al., 2004) and cactus pear juice (Cassano et al., 2007). The integration of MD with other membrane operations such as MF, UF, NF, RO and OD permits advantage of achieving high quality fruit juice concentrates with higher economic feasibility. The use of integrated membrane processes for clarification and concentration of citrus (orange and lemon) and carrot juices have been proposed by Cassano et al. (2003). A limpid phase has been produced by ultrafiltration pilot unit. The clarified permeate coming from UF has been concentrated up to $15-20^{\circ}$ Brix by RO with a laboratory scale unit. Finally, OD step was applied to yield $60-63^{\circ}$ Brix concentrate with a transmembrane flux of $1 \mathrm{~kg} / \mathrm{m}^{2} \mathrm{~h}$. A slight decrease in the total antioxidant activity has been reported during RO treatment, whereas no significant change was observed during OD treatment. Kozak et. al (2009) investigated an integrated approach for black currant juice concentration. The juice samples were prefiltered by $\mathrm{MF}$ and preconcentrated to $22^{\circ}$ Brix by RO. A further concentration of the retentate coming from $\mathrm{RO}$ was obtained by $\mathrm{MD}$ and black currant concentrate with $58.2{ }^{\circ}$ Brix was produced. Onsekizoglu et al. (2010b) have proposed the use of membrane processes for the production of clarified apple juice concentrate. The efficiency of UF was improved by an additional enzymatic pretreatment and flocculation step using fining agents such as gelatine and bentonite. The permeate coming from the UF with initial TSS contents of ca. $12{ }^{\circ}$ Brix were subsequently concentrated up to TSS contents of $65^{\circ} \mathrm{Brix}$ by MD, OD and coupled operation of MD \& OD processes. The effect of clarification and concentration processes on formation of 5-hydroxymethylfurfural (HMF), retention of bioactive compounds (phenolic compounds, organic acids, glucose, fructose and sucrose) and their efficiency in preserving natural color and aroma (trans-2-hexenal, the most relevant compound in apple juice aroma) were evaluated in order to maintain a high quality product. The new membrane based 
concentration techniques have been reported to be very efficient since the concentrated juice presented nutritional and sensorial quality very similar to that of the original juice especially regarding the retention of bright natural color and pleasant aroma, which were considerably lost during thermal evaporation. Further analysis have shown that the subsequent concentration treatments by MD, OD and coupled operation of MD \& OD processes did not induce any significant changes in phenolic compounds, organic acids and sugars independently on the final concentration achieved.

The MD process can be successfully applied to remove ethanol and the other volatile metabolites from the fermentation broth (Banat \& Al-Shannag, 2000; Gryta, 2001; Gryta \& Barancewicz, 2011; Gryta et al., 2000a; Tomaszewska \& Bialonczyk, 2011). The fermentation of sugar with Saccharomyces cerevisiae proceeds with the formation of by-products, which tend to inhibit the yeast productivity. The removal of ethanol is usually carried out by distillation. The primary disadvantages of the conventional process of ethanol generation include high energy consumption and excessive amount of wastewater discharged from the distillation columns. The MD process provides an economical alternative to the existing distillation technique for continuous removal of fermented products. The removal of volatile metabolites from the fermentation broth by MD process enables reduction of the inhibitory effect of these compounds on microbial culture together with an increased rate of sugar conversion to ethanol and hence the cost of further concentration of alcohol can be reduced. The main advantage of MD over conventional distillation processes is that membrane distillation takes place at a temperature below the normal boiling point of broth solutions.

Other food-related applications of MD include concentration of natural food colorants (Nayak \& Rastogi, 2010), dealcoholization of wine (Varavuth et al., 2009) and concentration of herbal and plant extracts (Cisse et al., 2011; Dornier et al., 2011; Johnson et al., 2002; Zhao et al., 2011).

\section{Concluding remarks and future prospects}

As a promising alternative to replace other separation processes, MD has gained much interest for its lower energy requirement in comparison with conventional distillation, lower operating pressures and higher rejection factors than in pressure driven processes such as $\mathrm{NF}$, and RO. Although MD has been known for more than 40 years, a number of problems exist when MD is considered for industrial implementation. Most of the conducted MD studies are still in the laboratory scale. In recent years, some pilot plant studies have been proposed for desalination (Blanco et al., 2011; Farmani et al., 2008; Song et al., 2008; Xu et al., 2006), however long term evaluations of pilot plant applications for the concentration and recovery of aqueous solutions containing volatile solutes especially in the food industry are still scarce. Therefore, achievement of high concentration levels in certain fruit juice samples taking into account the effects on mass and heat transfer mechanisms, membrane characteristics and the quality parameters together with a detailed economical analysis should be examined on a large scale.

On the other hand, there is a lack of commercially available MD units; practically all membrane modules are designed for other membrane operations (i.e. microfiltration) rather than MD. Novel membranes specifically designed for MD applications should be fabricated in an economically feasible way. Research on transmembrane flux enhancement (i.e. acoustic field) for large scale applications is required. More attention should be paid to the 
possibility of integrating MD to other separation techniques in order to improve the efficiency of the overall system and to make the process economically viable for industrial applications. For fruit juice concentration, coupled operation of MD and OD seems promising to overcome high temperature related problems (i.e. aroma and colour loss) encountered in MD. However, integration of MD with other MD variants as well as conventional distillation techniques has not yet been investigated. Hence more focus on such combinations is required. In recent years, coupling MD with solar energy systems has been well studied by various researchers for desalination of sea water.

The ability to effectively operate at low temperatures makes MD process possible to utilize low-grade waste and/or alternative energy sources. In recent years, coupling MD with solar, geothermal and waste energy systems has been proposed to decrease energy consumption in desalination systems. Such an approach may be crucial for food processing systems. For example, in the case of fruit juice concentration, much lower temperatures should be applied in order to obtain stable products able to retain as much possible the uniqueness of the fresh fruit, its original color, aroma, nutritional value and structural characteristics. Thus, the possibility of operating under very mild conditions enables MD to utilize various alternative energy sources, making it more promising for industrial application. Further efforts need to be concentrated in this field, especially in utilization of waste energy and/or other renewable energy sources in the view of industrial implementation.

\section{References}

Agashichev, S. P. (2006) Modeling of the concentration polarization in a cylindrical channel of an ultrafiltration module. Theoretical Foundations of Chemical Engineering, 40, 215216.

Ali, F., Dornier, M., Duquenoy, A. \& Reynes, M. (2003) Evaluating transfers of aroma compounds during the concentration of sucrose solutions by osmotic distillation in a batch-type pilot plant. Journal of Food Engineering, 60, 1-8.

Alklaibi, A. M. \& Lior, N. (2005) Membrane-distillation desalination: status and potential. Desalination, 171, 111-131.

Alves, V. D. \& Coelhoso, I. M. (2006) Orange juice concentration by osmotic evaporation and membrane distillation: A comparative study. Journal of Food Engineering, 74, 125133.

Babu, B. R., Rastogi, N. K. \& Raghavarao, K. S. M. S. (2006) Mass transfer in osmotic membrane distillation of phycocyanin colorant and sweet-lime juice. Journal of Membrane Science, 272, 58-69.

Babu, B. R., Rastogi, N. X. \& Raghavarao, K. S. M. S. (2008) Concentration and temperature polarization effects during osmotic membrane distillation. Journal of Membrane Science, 322, 146-153.

Bagger-Jorgensen, R., Meyer, A. S., Pinelo, M., Varming, C. \& Jonsson, G. (2011) Recovery of volatile fruit juice aroma compounds by membrane technology: Sweeping gas versus vacuum membrane distillation. Innovative Food Science $\mathcal{E}$ Emerging Technologies, 12, 388-397.

Bailey, A. F. G., Barbe, A. M., Hogan, P. A., Johnson, R. A. \& Sheng, J. (2000) The effect of ultrafiltration on the subsequent concentration of grape juice by osmotic distillation. Journal of Membrane Science, 164, 195-204. 
Banat, F. A. \& Al-Shannag, M. (2000) Recovery of dilute acetone-butanol-ethanol (ABE) solvents from aqueous solutions via membrane distillation. Bioprocess Engineering, 23, 643-649.

Banat, F. A. \& Simandl, J. (1999) Membrane distillation for dilute ethanol - Separation from aqueous streams. Journal of Membrane Science, 163, 333-348.

Bandini, S. \& Sarti, G. C. (1999) Heat and mass transport resistances in vacuum membrane distillation per drop. Aiche Journal, 45, 1422-1433.

Barbe, A. M., Hogan, P. A. \& Johnson, R. A. (2000) Surface morphology changes during initial usage of hydrophobic, microporous polypropylene membranes. Journal of Membrane Science, 172, 149-156.

Bazinet, L., Cossec, C., Gaudreau, H. \& Desjardins, Y. (2009) Production of a Phenolic Antioxidant Enriched Cranberry Juice by Electrodialysis with Filtration Membrane. Journal of Agricultural and Food Chemistry, 57, 10245-10251.

Belafi-Bako, K. \& Koroknai, B. (2006) Enhanced water flux in fruit juice concentration: Coupled operation of osmotic evaporation and membrane distillation. Journal of Membrane Science, 269, 187-193.

Blanco, J., Guillen-Burrieza, E., Zaragoza, G., Alarcon, D. C., Palenzuela, P., Ibarra, M. \& Gernjak, W. (2011) Experimental analysis of an air gap membrane distillation solar desalination pilot system. Journal of Membrane Science, 379, 386-396.

Brodard, F., Romero, J., Belleville, M. P., Sanchez, J., Combe-James, C., Dornier, M. \& Rios, G. M. (2003) New hydrophobic membranes for osmotic evaporation process. Separation and Purification Technology, 32, 3-7.

Bryjak, M., Gancarz, I. \& Pozniak, G. (2000) Plasma-modified porous membranes. Chemical Papers-Chemicke Zvesti, 54, 496-501.

Bui, A. V. \& Nguyen, H. M. (2005) Scaling Up of Osmotic Distillation from Laboratory to Pilot Plant for Concentration of Fruit Juices. International Journal of Food Engineering, 1, - .

Bui, V. A., Nguyen, M. H. \& Muller, J. (2004) A laboratory study on glucose concentration by osmotic distillation in hollow fibre module. Journal of Food Engineering, 63, 237-245.

Burgoyne, A. \& Vahdati, M. M. (2000) Direct contact membrane distillation. Separation Science and Technology, 35, 1257-1284.

Cabral, L. M. C., Pagani, M. M., Rocha-Leao, M. H., Couto, A. B. B., Pinto, J. P., Ribeiro, A. O. \& Gomes, F. D. (2011) Concentration of acerola (Malpighia emarginata DC.) juice by integrated membrane separation process. Desalination and Water Treatment, 27, 130-134.

Calabro, V. \& Drioli, E. (1997) Polarization phenomena in integrated reverse osmosis and membrane distillation for seawater desalination and waste water treatment. Desalination, 108, 81-82.

Calabro, V., Jiao, B. L. \& Drioli, E. (1994) Theoretical and Experimental-Study on Membrane Distillation in the Concentration of Orange Juice. Industrial $\mathcal{E}$ Engineering Chemistry Research, 33, 1803-1808.

Cassano, A., Conidi, C., Timpone, R., D'Avella, M. \& Drioli, E. (2007) A membrane-based process for the clarification and the concentration of the cactus pear juice. Journal of Food Engineering, 80, 914-921.

Cassano, A. \& Drioli, E. (2007) Concentration of clarified kiwifruit juice by osmotic distillation. Journal of Food Engineering, 79, 1397-1404.

Cassano, A., Drioli, E., Galaverna, G., Marchelli, R., Di Silvestro, G. \& Cagnasso, P. (2003) Clarification and concentration of citrus and carrot juices by integrated membrane processes. Journal of Food Engineering, 57, 153-163. 
Cath, T. Y., Adams, D. \& Childress, A. E. (2005) Membrane contactor processes for wastewater reclamation in space II. Combined direct osmosis, osmotic distillation, and membrane distillation for treatment of metabolic wastewater. Journal of Membrane Science, 257, 111-119.

Cath, T. Y., Adams, V. D. \& Childress, A. E. (2004) Experimental study of desalination using direct contact membrane distillation: a new approach to flux enhancement. Journal of Membrane Science, 228, 5-16.

Celere, M. \& Gostoli, C. (2004) Osmotic distillation with propylene glycol, glycerol and glycerol-salt mixtures. Journal of Membrane Science, 229, 159-170.

Chanachai, A., Meksup, K. \& Jiraratananon, R. (2010) Coating of hydrophobic hollow fiber PVDF membrane with chitosan for protection against wetting and flavor loss in osmotic distillation process. Separation and Purification Technology, 72, 217-224.

Chen, T. C., Ho, C. D. \& Yeh, H. M. (2009) Theoretical modeling and experimental analysis of direct contact membrane distillation. Journal of Membrane Science, 330, 279-287.

Chernyshov, M. N., Meindersma, G. W. \& de Haan, A. B. (2003) Modelling temperature and salt concentration distribution in membrane distillation feed channel. Desalination, 157, 315-324.

Chernyshov, M. N., Meindersma, G. W. \& de Haan, A. B. (2005) Comparison of spacers for temperature polarization reduction in air gap membrane distillation. Desalination, $183,363-374$.

Ciesarova, Z. \& Vranova, J. (2009) Furan in Food - a Review. Czech Journal of Food Sciences, $27,1-10$.

Cipollina, A., Micale, G. \& Rizzuti, L. (2011) Membrane distillation heat transfer enhancement by CFD analysis of internal module geometry. Desalination and Water Treatment, 25, 195-209.

Cisse, M., Vaillant, F., Bouquet, S., Pallet, D., Lutin, F., Reynes, M. \& Dornier, M. (2011) Athermal concentration by osmotic evaporation of roselle extract, apple and grape juices and impact on quality. Innovative Food Science \& Emerging Technologies, 12, 352-360.

Cisse, M., Vaillant, F., Perez, A., Dornier, M. \& Reynes, M. (2005) The quality of orange juice processed by coupling crossflow microfiltration and osmotic evaporation. International Journal of Food Science and Technology, 40, 105-116.

Close, E. \& Sorensen, E. (2010) Modelling of Direct Contact Membrane Distillation for Desalination. 20th European Symposium on Computer Aided Process Engineering, 28, 649-654.

Conidi, C., Cassano, A. \& Drioli, E. (2011) A membrane-based study for the recovery of polyphenols from bergamot juice. Journal of Membrane Science, 375, 182-190.

Courel, M., Dornier, M., Herry, J. M., Rios, G. M. \& Reynes, M. (2000) Effect of operating conditions on water transport during the concentration of sucrose solutions by osmotic distillation. Journal of Membrane Science, 170, 281-289.

Couto, D. S., Dornier, M., Pallet, D., Reynes, M., Dijoux, D., Freitas, S. P. \& Cabral, L. M. C. (2011) Evaluation of nanofiltration membranes for the retention of anthocyanins of acai (Euterpe oleracea Mart.) juice. Desalination and Water Treatment, 27, 108-113.

Crews, C. \& Castle, L. (2007) A review of the occurrence, formation and analysis of furan in heat-processed foods. Trends in Food Science \& Technology, 18, 365-372.

Criscuoli, A. \& Drioli, E. (1999) Energetic and exergetic analysis of an integrated membrane desalination system. Desalination, 124, 243-249. 
Criscuoli, A., Zhong, J., Figoli, A., Carnevale, M. C., Huang, R. \& Drioli, E. (2008) Treatment of dye solutions by vacuum membrane distillation. Water Research, 42, 5031-5037.

Curcio, E., Di, P. G. \& Enrico, D. (Eds.). (2010). Membrane distillation and osmotic distillation, Elsevier.

Curcio, E. \& Drioli, E. (2005) Membrane distillation and related operations - A review. Separation and Purification Reviews, 34, 35-86.

Ding, Z. W., Liu, L. Y., Liu, Z. \& Ma, R. Y. (2011) The use of intermittent gas bubbling to control membrane fouling in concentrating TCM extract by membrane distillation. Journal of Membrane Science, 372, 172-181.

Ding, Z. W., Liu, L. Y., Yu, H. F., Ma, R. Y. \& Yang, Z. R. (2008) Concentrating the extract of traditional Chinese medicine by direct contact membrane distillation. Journal of Membrane Science, 310, 539-549.

Ding, Z. W., Ma, R. Y. \& Fane, A. G. (2003) A new model for mass transfer in direct contact membrane distillation. Desalination, 151, 217-227.

Dornier, M., Cisse, M., Vaillant, F., Bouquet, S., Pallet, D., Lutin, F. \& Reynes, M. (2011) Athermal concentration by osmotic evaporation of roselle extract, apple and grape juices and impact on quality. Innovative Food Science \& Emerging Technologies, 12, 352-360.

Durham, R. J. \& Nguyen, M. H. (1994) Hydrophobic Membrane Evaluation and Cleaning for Osmotic Distillation of Tomato Puree. Journal of Membrane Science, 87, 181-189.

El-Bourawi, M. S., Ding, Z., Ma, R. \& Khayet, M. (2006) A framework for better understanding membrane distillation separation process. Journal of Membrane Science, 285, 4-29.

Farmani, B., Haddadekhodaparast, M. H., Hesari, J. \& Aharizad, S. (2008) Determining Optimum Conditions for Sugarcane Juice Refinement by Pilot Plant Dead-end Ceramic Micro-filtration. Journal of Agricultural Science and Technology, 10, 351-357.

Galaverna, G., Di Silvestro, G., Cassano, A., Sforza, S., Dossena, A., Drioli, E. \& Marchelli, R. (2008) A new integrated membrane process for the production of concentrated blood orange juice: Effect on bioactive compounds and antioxidant activity. Food Chemistry, 106, 1021-1030.

Garcia-Payo, M. C., Izquierdo-Gil, M. A. \& Fernandez-Pineda, C. (2000) Air gap membrane distillation of aqueous alcohol solutions. Journal of Membrane Science, 169, 61-80.

Gomes, F. D., da Costa, P. A., de Campos, M. B. D., Couri, S. \& Cabral, L. M. C. (2011) Concentration of watermelon juice by reverse osmosis process. Desalination and Water Treatment, 27, 120-122.

Gryta, M. (2001) The fermentation process integrated with membrane distillation. Separation and Purification Technology, 24, 283-296.

Gryta, M. (2005a) Long-term performance of membrane distillation process. Journal of Membrane Science, 265, 153-159.

Gryta, M. (2005b) Osmotic MD and other membrane distillation variants. Journal of Membrane Science, 246, 145-156.

Gryta, M. (2007) Influence of polypropylene membrane surface porosity on the performance of membrane distillation process. Journal of Membrane Science, 287, 67-78.

Gryta, M. (2008) Fouling in direct contact membrane distillation process. Journal of Membrane Science, 325, 383-394.

Gryta, M. (2010) Desalination of thermally softened water by membrane distillation process. Desalination, 257, 30-35. 
Gryta, M. \& Barancewicz, M. (2011) Separation of volatile compounds from fermentation broth by membrane distillation. Polish Journal of Chemical Technology, 13, 56-60.

Gryta, M., Morawski, A. W. \& Tomaszewska, M. (2000a) Ethanol production in membrane distillation bioreactor. Catalysis Today, 56, 159-165.

Gryta, M., Tomaszewska, M. \& Morawski, A. W. (2000b) A capillary module for membrane distillation process. Chemical Papers, 54, 370-374.

He, K., Hwang, H. J., Woo, M. W. \& Moon, I. S. (2011) Production of drinking water from saline water by direct contact membrane distillation (DCMD). Journal of Industrial and Engineering Chemistry, 17, 41-48.

Hogan, P. A., Canning, R. P., Peterson, P. A., Johnson, R. A. \& Michaels, A. S. (1998) A new option: Osmotic distillation. Chemical Engineering Progress, 94, 49-61.

Hongvaleerat, C., Cabral, L. M. C., Dornier, M., Reynes, M. \& Ningsanond, S. (2008) Concentration of pineapple juice by osmotic evaporation. Journal of Food Engineering, 88, 548-552.

Huo, R. T., Gu, Z. Y., Zuo, K. J. \& Zhao, G. M. (2010) Preparation and Humic Acid Fouling Resistance of Poly(vinylidene fluoride)-Fabric Composite Membranes for Membrane Distillation. Journal of Applied Polymer Science, 117, 3651-3658.

Huo, R. T., Gu, Z. Y., Zuo, K. J. \& Zhao, G. M. (2011) Fouling resistance of PVDF-fabric composite membrane in membrane distillation desalination. Advances in Composites, Pts 1 and 2, 150-151, 334-339.

Hwang, H. J., He, K., Gray, S., Zhang, J. H. \& Moon, I. S. (2011) Direct contact membrane distillation (DCMD): Experimental study on the commercial PTFE membrane and modeling. Journal of Membrane Science, 371, 90-98.

Ibarz, A., Garza, S., Garvin, A. \& Pagan, J. (2011) Degradation of mansarin juice concnetrates treated at high temperatures. Journal of Food Process Engineering, 34, 682-696.

Izquierdo-Gil, M. A., Garcia-Payo, M. C. \& Fernandez-Pineda, C. (1999) Air gap membrane distillation of sucrose aqueous solutions. Journal of Membrane Science, 155, 291-307.

Jiao, B., Cassano, A. \& Drioli, E. (2004) Recent advances on membrane processes for the concentration of fruit juices: a review. Journal of Food Engineering, 63, 303-324.

Johnson, R. A., Sun, J. C. \& Sun, J. (2002) A pervaporation-microfiltration-osmotic distillation hybrid process for the concentration of ethanol-water extracts of the Echinacea plant. Journal of Membrane Science, 209, 221-232.

Kadakal, C., Sebahattin, N. \& Poyrazoglu, E. S. (2002) Effect of commercial processing stages of apple juice on patulin, fumaric acid and hydroxymethylfurfural (HMF) levels. Journal of Food Quality, 25, 359-368.

Khayet, A., Matsuura, T., Mengual, J. I. \& Qtaishat, M. (2006) Design of novel direct contact membrane distillation membranes. Desalination, 192, 105-111.

Khayet, M. (2011) Membranes and theoretical modeling of membrane distillation: A review. Advances in Colloid and Interface Science, 164, 56-88.

Khayet, M., Cojocaru, C. \& Garcia-Payo, M. C. (2010) Experimental design and optimization of asymmetric flat-sheet membranes prepared for direct contact membrane distillation. Journal of Membrane Science, 351, 234-245.

Khayet, M., Khulbe, K. C. \& Matsuura, T. (2004a) Characterization of membranes for membrane distillation by atomic force microscopy and estimation of their water vapor transfer coefficients in vacuum membrane distillation process. Journal of Membrane Science, 238, 199-211. 
Khayet, M., Velazquez, A. \& Mengual, J. I. (2004b) Direct contact membrane distillation of humic acid solutions. Journal of Membrane Science, 240, 123-128.

Khayet, M. S. \& Matsuura, T. 2011. Membrane distillation: principles and applications. Elsevier.

Kim, S. S. \& Lloyd, D. R. (1991) Microporous membrane formation via thermally-induced phase separation. 3. Effect of thermodynamic interactions on the structure of isotactic polypropylene membranes. Journal of Membrane Science, 64, 13-29.

Kong, Y., Lin, X., Wu, Y. L., Chen, J. \& Xu, J. P. (1992) Plasma Polymerization of Octafluorocyclobutane and Hydrophobic Microporous Composite Membranes for Membrane Distillation. Journal of Applied Polymer Science, 46, 191-199.

Kozak, A., Bekassy-Molnar, E. \& Vatai, G. (2009) Production of black-currant juice concentrate by using membrane distillation. Desalination, 241, 309-314.

Krajewski, S. R., Kujawski, W., Bukowska, M., Picard, C. \& Larbot, A. (2006) Application of fluoroalkylsilanes (FAS) grafted ceramic membranes in membrane distillation process of $\mathrm{NaCl}$ solutions. Journal of Membrane Science, 281, 253-259.

Kullab, A. \& Martin, A. (2011) Membrane distillation and applications for water purification in thermal cogeneration plants. Separation and Purification Technology, 76, 231-237.

Lagana, F., Barbieri, G. \& Drioli, E. (2000) Direct contact membrane distillation: modelling and concentration experiments. Journal of Membrane Science, 166, 1-11.

Lai, C. L., Liou, R. M., Chen, S. H., Huang, G. W. \& Lee, K. R. (2011) Preparation and characterization of plasma-modified PTFE membrane and its application in direct contact membrane distillation. Desalination, 267, 184-192.

Lawson, K. W., Hall, M. S. \& Lloyd, D. R. (1995) Compaction of Microporous Membranes Used in Membrane Distillation .1. Effect on Gas-Permeability. Journal of Membrane Science, 101, 99-108.

Lawson, K. W. \& Lloyd, D. R. (1996a) Membrane distillation .1. Module design and performance evaluation using vacuum membrane distillation. Journal of Membrane Science, 120, 111-121.

Lawson, K. W. \& Lloyd, D. R. (1996b) Membrane distillation .2. Direct contact MD. Journal of Membrane Science, 120, 123-133.

Lawson, K. W. \& Lloyd, D. R. (1997) Membrane distillation. Journal of Membrane Science, 124, $1-25$.

Li, B. \& Sirkar, K. K. (2004) Novel membrane and device for direct contact membrane distillation-based desalination process. Industrial $\mathcal{E}$ Engineering Chemistry Research, 43, 5300-5309.

Li, B. \& Sirkar, K. K. (2005) Novel membrane and device for vacuum membrane distillationbased desalination process. Journal of Membrane Science, 257, 60-75.

Li, N. N., Fane, A. G., Ho, W. S. W. \& Matsuura, T. (Eds.). (2008). Advanced Membrane Technology and Applications, John Wiley \& Sons Inc., New Jersey.

Liu, F., Hashim, N. A., Liu, Y. T., Abed, M. R. M. \& Li, K. (2011) Progress in the production and modification of PVDF membranes. Journal of Membrane Science, 375, 1-27.

Lukanin, E. S., Gunko, S. M., Bryk, M. T. \& Nigmatullin, R. R. (2003) The effect of content of apple juice biopolymers on the concentration by membrane distillation. Journal of Food Engineering, 60, 275-280.

Mansouri, J. \& Fane, A. G. (1999) Osmotic distillation of oily feeds. Journal of Membrane Science, 153, 103-120. 
Martinetti, C. R., Childress, A. E. \& Cath, T. Y. (2009) High recovery of concentrated RO brines using forward osmosis and membrane distillation. Journal of Membrane Science, 331, 31-39.

Martinez-Diez, L., Vazquez-Gonzalez, M. I. \& Florido-Diaz, F. J. (1998) Study of membrane distillation using channel spacers. Journal of Membrane Science, 144, 45-56.

Martinez, L., Florido-Diaz, F. J., Hernandez, A. \& Pradanos, P. (2002) Characterisation of three hydrophobic porous membranes used in membrane distillation - Modelling and evaluation of their water vapour permeabilities. Journal of Membrane Science, 203, 15-27.

Martinez, L. \& Rodriguez-Maroto, J. M. (2006) Characterization of membrane distillation modules and analysis of mass flux enhancement by channel spacers. Journal of Membrane Science, 274, 123-137.

Martinez, L. \& Rodriguez-Maroto, J. M. (2007) On transport resistances in direct contact membrane distillation. Journal of Membrane Science, 295, 28-39.

Mello, B., Petrus, J. C. C. \& Hubinger, M. D. (2010) Performance of nanofiltration concentration process in propolis extracts. Ciencia E Tecnologia De Alimentos, 30, 166172.

Mengual, J. I., Dezarate, J. M. O., Pena, L. \& Velazquez, A. (1993) Osmotic Distillation through Porous Hydrophobic Membranes. Journal of Membrane Science, 82, 129-140.

Mericq, J. P., Laborie, S. \& Cabassud, C. (2009) Vacuum membrane distillation for an integrated seawater desalination process. Desalination and Water Treatment, 9, 287296.

Meyer, A. S., Bagger-Jorgensen, R., Pinelo, M., Varming, C. \& Jonsson, G. (2011) Recovery of volatile fruit juice aroma compounds by membrane technology: Sweeping gas versus vacuum membrane distillation. Innovative Food Science $\mathcal{E}$ Emerging Technologies, 12, 388-397.

Moon, I. S., Hwang, H. J., He, K., Gray, S. \& Zhang, J. H. (2011) Direct contact membrane distillation (DCMD): Experimental study on the commercial PTFE membrane and modeling. Journal of Membrane Science, 371, 90-98.

Morao, A. I. C., Alves, A. M. B. \& Geraldes, V. (2008) Concentration polarization in a reverse osmosis/nanofiltration plate-and-frame membrane module. Journal of Membrane Science, 325, 580-591.

Nagaraj, N., Patil, B. S. \& Biradar, P. M. (2006a) Osmotic Membrane Distillation - A Brief Review. International Journal of Food Engineering, 2.

Nagaraj, N., Patil, G., Babu, B. R., Hebbar, U. H., Raghavarao, K. S. M. S. \& Nene, S. (2006b) Mass transfer in osmotic membrane distillation. Journal of Membrane Science, 268, 4856.

Narayan, A. V., Nagaraj, N., Hebbar, H. U., Chakkaravarthi, A., Raghavarao, K. S. M. S. \& Nene, S. (2002) Acoustic field-assisted osmotic membrane distillation. Desalination, $147,149-156$.

Nayak, C. A. \& Rastogi, N. K. (2010) Comparison of osmotic membrane distillation and forward osmosis membrane processes for concentration of anthocyanin. Desalination and Water Treatment, 16, 134-145.

Nene, S., Kaur, S., Sumod, K., Joshi, B. \& Raghavarao, K. S. M. S. (2004) Membrane distillation for the concentration of raw cane-sugar syrup and membrane clarified sugarcane juice (vol 147, pg 157, 2002). Desalination, 161, 305-305.

Oliver, M. R. 2004. Chemical-mechanical planarization of semiconductor materials Springer. 
Onsekizoglu, P., Bahceci, K. S. \& Acar, J. (2010a) The use of factorial design for modeling membrane distillation. Journal of Membrane Science, 349, 225-230.

Onsekizoglu, P., Bahceci, K. S. \& Acar, M. J. (2010b) Clarification and the concentration of apple juice using membrane processes: A comparative quality assessment. Journal of Membrane Science, 352, 160-165.

Onsekizoglu, P. (2011) A novel integrated membrane process for pomegranate juice concentration, Proceedings of Novel Approaches in Food Industry, Cesme, Izmir, Turkey, May 2011

Pabby, A. K., Rizvi, S. S. H. \& Sastre, A. M. (Eds.). (2009). Handbook of Membrane Seperations, CRC Press, New York.

Peinemann, K.-V., Nunes, S. P. \& Giorno, L. (Eds.). (2010). Membrane Technology: Volume 3: Membranes for Food Applications, Wiley-VCH Verlag GmbH \& Co. KGaA, Germany.

Phattaranawik, J., Fane, A. G., Pasquier, A. C. S., Bing, W. \& Wong, F. S. (2009) Experimental Study and Design of a Submerged Membrane Distillation Bioreactor. Chemical Engineering \& Technology, 32, 38-44.

Phattaranawik, J. \& Jiraratananon, R. (2001) Direct contact membrane distillation: effect of mass transfer on heat transfer. Journal of Membrane Science, 188, 137-143.

Phattaranawik, J., Jiraratananon, R. \& Fane, A. G. (2003a) Effect of pore size distribution and air flux on mass transport in direct contact membrane distillation. Journal of Membrane Science, 215, 75-85.

Phattaranawik, J., Jiraratananon, R. \& Fane, A. G. (2003b) Heat transport and membrane distillation coefficients in direct contact membrane distillation. Journal of Membrane Science, 212, 177-193.

Phattaranawik, J., Jiraratananon, R., Fane, A. G. \& Halim, C. (2001) Mass flux enhancement using spacer filled channels in direct contact membrane distillation. Journal of Membrane Science, 187, 193-201.

Qtaishat, M., Khayet, M. \& Matsuura, T. (2009) Guidelines for preparation of higher flux hydrophobic/hydrophilic composite membranes for membrane distillation. Journal of Membrane Science, 329, 193-200.

Qtaishat, M., Matsuura, T., Kruczek, B. \& Khayet, A. (2008) Heat and mass transfer analysis in direct contact membrane distillation. Desalination, 219, 272-292.

Quoc, A. L., Mondor, M., Lamarche, F. \& Makhlouf, J. (2011) Optimization of electrodialysis with bipolar membranes applied to cloudy apple juice: Minimization of malic acid and sugar losses. Innovative Food Science \& Emerging Technologies, 12, 45-49.

Rektor, A., Kozak, A., Vatai, G. \& Bekassy-Molnar, E. (2007) Pilot plant RO-filtration of grape juice. Separation and Purification Technology, 57, 473-475.

Rincon, C., de Zarate, J. M. O. \& Mengual, J. I. (1999) Separation of water and glycols by direct contact membrane distillation. Journal of Membrane Science, 158, 155-165.

Rodrigues, R. B., Menezes, H. C., Cabral, L. M. C., Dornier, M., Rios, G. M. \& Reynes, M. (2004) Evaluation of reverse osmosis and osmotic evaporation to concentrate camucamu juice (Myrciaria dubia). Journal of Food Engineering, 63, 97-102.

Santana, I., Gurak, P. D., da Matta, V. M., Freitas, S. P. \& Cabral, L. M. C. (2011) Concentration of grape juice (Vitis labrusca) by reverse osmosis process. Desalination and Water Treatment, 27, 103-107.

Schofield, R. W., Fane, A. G. \& Fell, C. J. D. (1990a) Gas and Vapor Transport through Microporous Membranes .2. Membrane Distillation. Journal of Membrane Science, 53, 173-185. 
Schofield, R. W., Fane, A. G., Fell, C. J. D. \& Macoun, R. (1990b) Factors Affecting Flux in Membrane Distillation. Desalination, 77, 279-294.

Shaw, P. E., Lebrun, M., Ducamp, M. N., Jordan, M. J. \& Goodner, K. L. (2002) Pineapple juice concentrated by osmotic evaporation. Journal of Food Quality, 25, 39-49.

Shin, C. H. \& Johnson, R. (2007) Identification of an appropriate osmotic agent for use in osmotic distillation. Journal of Industrial and Engineering Chemistry, 13, 926-931.

Sigurdsson, S. \& Shishoo, R. (1997) Surface properties of polymers treated with tetrafluoromethane plasma. Journal of Applied Polymer Science, 66, 1591-1601.

Simsek, A., Poyrazoglu, E. S., Karacan, S. \& Velioglu, Y. S. (2007) Response surface methodological study on HMF and fluorescent accumulation in red and white grape juices and concentrates. Food Chemistry, 101, 987-994.

Song, L. F. (2010) Concentration Polarization in a Narrow Reverse Osmosis Membrane Channel. Aiche Journal, 56, 143-149.

Song, L. M., Ma, Z. D., Liao, X. H., Kosaraju, P. B., Irish, J. R. \& Sirkar, K. K. (2008) Pilot plant studies of novel membranes and devices for direct contact membrane distillationbased desalination. Journal of Membrane Science, 323, 257-270.

Srisurichan, S., Jiraratananon, R. \& Fane, A. G. (2006) Mass transfer mechanisms and transport resistances in direct contact membrane distillation process. Journal of Membrane Science, 277, 186-194.

Susanto, H. (2011) Towards practical implementations of membrane distillation. Chemical Engineering and Processing, 50, 139-150.

Teoh, M. M., Bonyadi, S. \& Chung, T. S. (2008) Investigation of different hollow fiber module designs for flux enhancement in the membrane distillation process. Journal of Membrane Science, 311, 371-379.

Tomaszewska, M. (2000) Membrane distillation - Examples of applications in technology and environmental protection. Polish Journal of Environmental Studies, 9, 27-36.

Tomaszewska, M. \& Bialonczyk, L. (2011) The investigation of ethanol separation by the membrane distillation process. Polish Journal of Chemical Technology, 13, 66-69.

Toribio, J. L. \& Lozano, J. E. (1986) Heat-induced browning of clarified apple juice at high temperatures. Journal of Food Science, 51, 172-\&.

Vaillant, F., Jeanton, E., Dornier, M., O'Brien, G. M., Reynes, M. \& Decloux, M. (2001) Concentration of passion fruit juice on an industrial pilot scale using osmotic evaporation. Journal of Food Engineering, 47, 195-202.

Valdes, H., Romero, J., Saavedra, A., Plaza, A. \& Bubnovich, V. (2009) Concentration of noni juice by means of osmotic distillation. Journal of Membrane Science, 330, 205-213.

Varavuth, S., Jiraratananon, R. \& Atchariyawut, S. (2009) Experimental study on dealcoholization of wine by osmotic distillation process. Separation and Purification Technology, 66, 313-321.

Vargas-Garcia, A., Torrestiana-Sanchez, B., Garcia-Borquez, A. \& Aguilar-Uscanga, G. (2011) Effect of grafting on microstructure, composition and surface and transport properties of ceramic membranes for osmotic evaporation. Separation and Purification Technology, 80, 473-481.

Varming, C., Andersen, M. L. \& Poll, L. (2004) Influence of thermal treatment on black currant (Ribes nigrum L.) juice aroma. Journal of Agricultural and Food Chemistry, 52, 7628-7636.

Walton, J., Lu, H., Turner, C., Solis, S. \& Hein, H. 2004. Solar and waste heat desalination by membrane distillation. El Paso: College of Engineering University of Texas. 
Wang, C. C. (2011) On the heat transfer correlation for membrane distillation. Energy Conversion and Management, 52, 1968-1973.

Wang, F. L. \& Tarabara, V. V. (2007) Coupled effects of colloidal deposition and salt concentration polarization on reverse osmosis membrane performance. Journal of Membrane Science, 293, 111-123.

Wang, K. Y., Foo, S. W. \& Chung, T. S. (2009) Mixed Matrix PVDF Hollow Fiber Membranes with Nanoscale Pores for Desalination through Direct Contact Membrane Distillation. Industrial \& Engineering Chemistry Research, 48, 4474-4483.

Wang, K. Y., Teoh, M. M., Nugroho, A. \& Chung, T. S. (2011) Integrated forward osmosismembrane distillation (FO-MD) hybrid system for the concentration of protein solutions. Chemical Engineering Science, 66, 2421-2430.

Warczok, J., Gierszewska, M., Kujawski, W. \& Gueell, C. (2007) Application of osmotic membrane distillation for reconcentration of sugar solutions from osmotic dehydration. Separation and Purification Technology, 57, 425-429.

Winter, D., Koschikowski, J. \& Wieghaus, M. (2011) Desalination using membrane distillation: Experimental studies on full scale spiral wound modules. Journal of Membrane Science, 375, 104-112.

Wu, Y. L., Kong, Y., Lin, X., Liu, W. H. \& Xu, J. P. (1992) Surface-Modified Hydrophilic Membranes in Membrane Distillation. Journal of Membrane Science, 72, 189-196.

Xu, J. B., Lange, S., Bartley, J. P. \& Johnson, R. A. (2004) Alginate-coated microporous PTFE membranes for use in the osmotic distillation of oily feeds. Journal of Membrane Science, 240, 81-89.

Xu, Y., Zhu, B. K. \& Xu, Y. Y. (2006) Pilot test of vacuum membrane distillation for seawater desalination on a ship. Desalination, 189, 165-169.

Yang, X., Wang, R. \& Fane, A. G. (2011a) Novel designs for improving the performance of hollow fiber membrane distillation modules. Journal of Membrane Science, 384, 52-62.

Yang, X., Wang, R., Shi, L., Fane, A. G. \& Debowski, M. (2011b) Performance improvement of PVDF hollow fiber-based membrane distillation process. Journal of Membrane Science, 369, 437-447.

Yarlagadda, S., Gude, V. G., Camacho, L. M., Pinappu, S. \& Deng, S. G. (2011) Potable water recovery from As, $\mathrm{U}$, and $\mathrm{F}$ contaminated ground waters by direct contact membrane distillation process. Journal of Hazardous Materials, 192, 1388-1394.

Yasuda, T., Okuno, T. \& Yasuda, H. (1994) CONTACT-ANGLE OF WATER ON POLYMER SURFACES. Langmuir, 10, 2435-2439.

Zaamouche, R., Beicha, A. \& Sulaiman, N. M. (2009) Cross-Flow Ultrafiltration Model Based on Concentration Polarization. Journal of Chemical Engineering of Japan, 42, 107-110.

Zhang, J. H., Dow, N., Duke, M., Ostarcevic, E., Li, J. D. \& Gray, S. (2010) Identification of material and physical features of membrane distillation membranes for high performance desalination. Journal of Membrane Science, 349, 295-303.

Zhao, Z. P., Zhu, C. Y., Liu, D. Z. \& Liu, W. F. (2011) Concentration of ginseng extracts aqueous solution by vacuum membrane distillation 2 . Theory analysis of critical operating conditions and experimental confirmation. Desalination, 267, 147-153.

Zhigang, L., Biaohua, C. \& Zhongwei, D. 2005. Special distillation processes. The Netherlands: Elsevier.

Zolotarev, P. P., Ugrozov, V. V., Volkina, I. B. \& Nikulin, V. N. (1994) Treatment of WasteWater for Removing Heavy-Metals by Membrane Distillation. Journal of Hazardous Materials, 37, 77-82. 


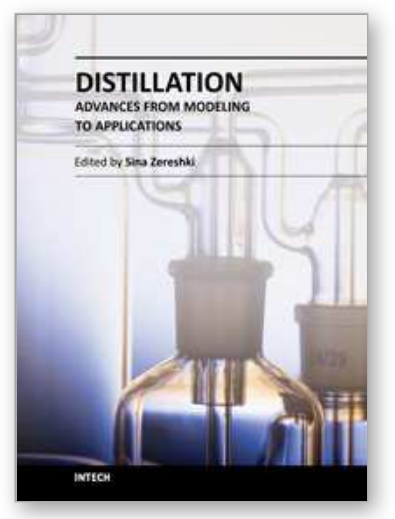

\author{
Distillation - Advances from Modeling to Applications \\ Edited by Dr. Sina Zereshki
}

ISBN 978-953-51-0428-5

Hard cover, 282 pages

Publisher InTech

Published online 23, March, 2012

Published in print edition March, 2012

Distillation modeling and several applications mostly in food processing field are discussed under three sections in the present book. The provided modeling chapters aimed both the thermodynamic mathematical fundamentals and the simulation of distillation process. The practical experiences and case studies involve mainly the food and beverage industry and odor and aroma extraction. This book could certainly give the interested researchers in distillation field a useful insight.

\title{
How to reference
}

In order to correctly reference this scholarly work, feel free to copy and paste the following:

Pelin Onsekizoglu (2012). Membrane Distillation: Principle, Advances, Limitations and Future Prospects in Food Industry, Distillation - Advances from Modeling to Applications, Dr. Sina Zereshki (Ed.), ISBN: 978-95351-0428-5, InTech, Available from: http://www.intechopen.com/books/distillation-advances-from-modeling-toapplications/membrane-distillation-principle-advances-limitations-and-future-prospects-in-food-industry

\section{INTECH}

open science | open minds

\section{InTech Europe}

University Campus STeP Ri

Slavka Krautzeka 83/A

51000 Rijeka, Croatia

Phone: +385 (51) 770447

Fax: +385 (51) 686166

www.intechopen.com

\section{InTech China}

Unit 405, Office Block, Hotel Equatorial Shanghai

No.65, Yan An Road (West), Shanghai, 200040, China

中国上海市延安西路65号上海国际贵都大饭店办公楼 405 单元

Phone: +86-21-62489820

Fax: $+86-21-62489821$ 
(C) 2012 The Author(s). Licensee IntechOpen. This is an open access article distributed under the terms of the Creative Commons Attribution 3.0 License, which permits unrestricted use, distribution, and reproduction in any medium, provided the original work is properly cited. 